\title{
The Structure of Comparison in the Study of Revolution*
}

\author{
Sociological Theory, Forthcoming \\ Colin J. Beck \\ Pomona College
}

\begin{abstract}
The social scientific study of revolution has been deviled by a lack of progress in recent years, divided between competing views on the universality of patterns in revolution. This study examines the origins of these epistemologies. Drawing on an insight that different modes of comparison yield different types of knowledge, this study argues that the network structure of how cases are compared constrains or enables the development of a field's theoretical sensibilities. Analysis of comparative studies of revolution published from 1970 to 2009 reveals that the field overall is most amenable to knowledge about particular cases rather than the phenomenon of revolution broadly. Analysis of the changing structure of comparison over time reveals that comparison precedes the development of an epistemology. The results suggest that conclusions about the possibility, or lack thereof, of generalization may be an artifact of the comparative method.
\end{abstract}

* Adress correspondence to: Colin J. Beck, Department of Sociology, Pomona College, 420 N. Harvard Ave, Claremont, CA 91711, cbeck@pomona.edu. The author thanks Reuben J. Thomas, Nicholas Hoover Wilson, Charles Ragin, Henning Hillmann, Isaac Reed, John W. Meyer, Evan Schofer, and Robin M. Cooper for their extensive comments. Previous versions were presented at the Social Science History Association meeting in 2010, the Irvine Comparative Sociology Workshop in 2013, and the American Sociological Association Annual Meeting in 2014 and 2015. 


\section{Introduction}

With the sudden onset of the 2011 "Arab Spring" in the Middle East and North Africa, the phenomenon of revolution has new life in the social sciences. Recent accounts of the events stress various causal dimensions: weak states and divided elites (Goldstone 2013; Goodwin 2011; Mann 2013; Ritter 2015), processes of contagion and diffusion (Beck 2014; Diani 2011; Hale 2013), strengths of movements and coalitions (Austin Holmes 2012; Foran 2014; Lawson 2015; Leenders 2012), and the contingency of collective action (Kurzman 2012; Weyland 2012). Each of these explanations has their roots in years-old paradigms for understanding revolution. Scholars of revolution have known for decades that weak states and elite schisms can generate revolution (e.g., Goldstone 1991; Goodwin 2001; Skocpol 1979) and that contention can spread from one society to another (e.g., Katz 1997; Markoff 1996; Sohrabi 2002). Similarly, coalitions have long been a hallmark of revolution studies (Dix 1984; Foran 2005; Markoff 1988), and the importance of contingent processes for understanding revolution are over a decade old (Keddie 1995; Kuran 1995; Kurzman 1996). Theorization of revolution in general therefore appears to have slowed to a crawl (Lawson 2016).

The lack of progress in revolution theory has signaled different things to different scholars. On the one hand, it is interpreted to mean that generalizable models of revolution should be created, either through the incorporation of new factors and causes (Beck 2014; Goldstone 1998, 2003; Halliday 1999; Lawson 2016) or through the parsimony of necessary and sufficient causation (Goodwin 2001; Mann 2013). On the other hand, others take the lack of progress to be evidence of the failure of generalizable propositions, and thus emphasize the inherent uniqueness of revolutionary events (Ermakoff 2015; Kurzman 2004; McAdam, Tarrow, and Tilly 2001).

The meta-theoretical stances of these two views on revolution extend beyond the results of any one study or the propositions of any one theory. Rather, they are epistemological and ontological positions. As in social science in general, each perspective affects which events are to be considered part of the phenomenon in question, what the purposes of research should be, and which type of theories can be developed (Reed 2011).

I draw on a classic insight from Skopcol and Somers (1980)—that different analytical stances necessitate different sorts of comparisons - to explore the origins of the contemporary epistemologies in revolution theory. I argue that the logic of Skocpol and Somers can be inverted. That is, different types of comparison are more or less likely to lend themselves to different types of knowledge and the development of different epistemologies. This argument is essentially about inductivism in social scientific research. In comparative methodology, cases are investigated and theories developed in an iterative fashion (George and Bennett 2005; Goertz and Mahoney 2012). As such, theories reflect cases as much as deductive first principles. Which cases have been investigated and which comparisons have 
been drawn therefore will structure the development of theory for the individual study. A parallel process occurs at the level of a comparative field. Here, the underlying patterns of multiple studies' comparisons will structure a field's epistemological stances. In short, comparison precedes epistemology.

To substantiate the argument, I employ two analytical approaches. The first is to consider a knowledge system as a whole with a life of its own beyond the individual study. Conceptualizing knowledge this way is a classic approach in the sociology of science (Abbott 2001:Ch. 1; Collins 2000:Ch. 15; Kuhn 1962; Reed 2011), and distinct from approaches that consider the complex ways knowledge is made by scholars rooted in particular social sites (see Camic, Gross, and Lamont 2012; e.g., Bourdieu 2004; Latour 1987; Merton 1973). This way of thinking contrasts to the cottage industry of comparative-historical methodologists, which tends to focus on the lessons of singular noteworthy studies (e.g., Collier and Mahoney 1996; Geddes 1990; Mahoney 1999, 2000; Parigi and Henson n.d.). In contrast, the argument here is at the level of the field - an epistemology rather than a theory, a universe of cases rather than a singular case comparison.

Thinking of a field as a whole system leads to the second analytical approach. I conceptualize comparison as a network of cases, suited for the tools of social network analysis. Cases do not just exist in comparative studies as independent units-rather they lie in interdependent webs of comparison. This conceptualization is commensurate with a relational sociological approach, which emphasizes the dynamics between social entities (see Emirbayer 1997). A comparison between cases sets a relation between them, and the appearance of a case in multiple studies links the latter together. With repeated and new comparisons across a universe of cases, a network of ties develops. It is the resulting structure of comparison that undergirds an entire comparative field's theoretical development. The structure of this network, its cases, and their evolution over time reveals what type of knowledge about revolution can, and should be expected to, develop.

The argument here is thus one of macro-macro causation (see Jepperson and Meyer 2011). As such, I examine all identifiable comparative case studies of revolution published in English between 1970 and 2009. The data are both novel and robust as they cover an entire field of comparative study in its modern incarnation. And it follows in the tradition of methodological reflection by comparative-historical sociologists (see, e.g., Adams, Clemens, and Orloff 2005; Goertz and Mahoney 2012; Steinmetz 2004), of which revolution studies are no small part (Goldstone 2003).

The investigation yields a few key findings. First, the field of revolution has a clear preference for particular types of cases. Surprisingly, however, these are not the great revolutions of old but modern events, particularly those with leftist bases or insurgent modes of contention. For example, the Nicaraguan Revolution of 1979 is the most studied case. Second, comparison displays great homophily. Cases that are similar to each other are the 
most likely to be compared, and clusters of compared cases tend to fall within spatial and temporal boundaries. Third, analysis of change in the field over time confirms that the structure of comparison precedes the development of a meta-theoretical position, and suggests increasing fragmentation in revolution studies in the last decade. Altogether, the results indicate that the study of revolution is not well positioned to adjudicate between competing epistemologies. The possibility, or lack thereof, of generalizability remains an open question.

In the sections that follow, I first describe the contemporary epistemologies of revolution and how comparison can be conceptualized as a network. After presenting the sources of data and methodological details, I analyze which cases have been studied and the network structure of comparison overall. Second, I employ parallel analyses to show how the structure of the comparative field has changed over time. I then explore an implication of the analysis by considering how well the cases that have been studied might represent the actual universe of revolution. From these analyses, I argue that the empirical basis of the field precedes the development of its epistemologies and affects the type of knowledge that is accumulated. I conclude with a discussion of the implications for the social science of revolution, lessons for comparative-historical methodology more broadly, and possible extensions along the lines of the sociology of science.

\section{Epistemologies of Revolution and the Structure of Comparison}

Since the origins of social science, the study of revolution has undergone four primary generations of scholarship (Goldstone 1982, 2001). The earliest generations included the natural histories of revolution (e.g., Brinton 1938; Edwards 1927; Pettee 1938), and the general approaches of social strain theory (e.g., Davies 1962; Gurr 1970; Huntington 1968; Smelser 1962). By the 1970s, which begins the time period this study investigates, an early third generation structuralist, sometimes Marxist, account of revolution emerged (e.g., Moore 1966; Paige 1975; Snyder and Tilly 1972; Tilly 1964; Wolf 1969). In 1979, Theda Skocpol (1979) published States and Social Revolutions, which ushered in a new paradigm for understanding revolution - state breakdown theory. Skocpol's parsimonious definition of what constitutes a "social revolution" animated scholarship, and gave it a clear object of focus. State-centered theories of revolution thus dominated the field for over a decade (e.g., Goldstone 1991; Goodwin 2001), and constituted the highpoint of the third generation of revolution theory.

However, discontent with a state-centered view grew, particularly in its most abstract formulations. Scholars turned towards theories which explored the capacity of challengers to mobilize and the role of contingency and historical accident (e.g., Foran and Goodwin 1993; Kuran 1995; Kurzman 1996; Parsa 2000; Reed and Foran 2002; Selbin 1993; Weyland 2009). This work, while accompanying the cultural and agentic turn in social 
science, was also influenced by a new way of thinking about causality. Tilly $(1995,2001)$ proposed that social science should reject abstract generalizations in favor of mechanisms that could combine and recombine in different fashions in different cases. As the view developed, so did the types of mobilization considered analyzable as revolutions-failed mobilizations and negative cases (Foran 2005; Goodwin 2001; Tilly 1993), electoral and pacted transitions (Lawson 2005), and nonviolent mass protest (Beissinger 2013; Nepstad 2011; Ritter 2015; Stephan and Chenoweth 2008; Zunes 1994). These post-state breakdown theories constitute what is known as the fourth generation of revolution theory (Foran 1993; Goldstone 2001; Lawson 2016).

The third and fourth generations of revolution theory were each accompanied by a broader epistemology. As with any epistemology, there was a sense of what a revolution is and what the purposes of investigation should be. Certainly, specific theories diverged from the general framework of the generation but the overall thrust was clear. This is what makes them generations, after all (Clemens 2007; Goldstone 1982). The primary dividing line between the most recent generations is whether or not there are universal causes of revolution. Third generation structuralists sought generalizability across time and space, while fourth generation scholars have emphasized the inherent uniqueness of events, often due to agency and contingency. This debate remains unresolved today (Lawson 2016). Thus, both epistemologies persist as the Arab Spring is considered: universalists (e.g., Mann 2013; Ritter 2015) and particularists (e.g., Ermakoff 2015; Kurzman 2012)

I prefer not to refer to the epistemic divide as one of generalizability. First, generalizability is a loaded word in comparative social science, and, second, it is usually thought of as a property of a specific theoretical proposition. More fitting terms, when thinking about the overall theoretical style of a generation, may be what Parigi and Henson (n.d.) term "portable" knowledge and "grounded" knowledge. Portable knowledge is that which is applicable to instances beyond the cases of its initial development. Grounded knowledge remains much closer to its cases and sets tighter bounds on its applicability elsewhere. These are ideal-types. Any given study may display some degree of portability and groundedness in its analysis. And other words could be used, such as universal or particular, general or specific. Yet at the level of the field as a whole, I find the terminology of portable and grounded fitting to describe broad sensibilities. That is to say, they provide a way to characterize an epistemology without drawing claims about the specific nature of its individual theoretical propositions. I thus use portability and groundedness to characterize the generations of revolution theory, without making claims about the nature of the individual studies within each generation. For instance, state-centered theory tend towards an epistemology of portability - that revolutions have some general and universal patternsand theory of contingency tend towards an epistemology of groundedness-that revolutions depend on particular, historically-bounded contingencies. 
What accounts for the continued epistemic division between portability and groundedness in contemporary revolution theory? To address this question, I rely on an insight from Skocpol and Somers (1980) that different styles of comparative history necessitate different types of cases and comparison. They identify three different modes of analysis. The first is "parallel demonstration of theory" where the researcher juxtaposes various instances to show that a theory applies to all cases that it logically ought to fit. Cases examined thus represent many possible comparisons across a range of types (Skocpol and Somers 1980:176). This method tends to generate portable knowledge as its very intent is generalizability. The second mode of analysis is that of "contrast of contexts". Here cases are used to highlight their unique features and show how their uniqueness affects the theoretical propositions, with comparison usually controlling for geography or era (Skocpol and Somers 1980:178). Contrast of contexts is likely to make grounded knowledge close to its cases, as this is its very intent. Finally, there is "macro-causal analysis" that seeks to provide causal inferences about larger processes. Cases are used to show the veracity of an explanation, and comparison seeks to control for other factors by placing some historical bounds on investigation, often familial types (Skocpol and Somers 1980:182-84). This yields some portability in knowledge but with some groundedness due to its familial typical boundaries. Taken together, the three analytical styles form a triangle of comparative history (see Skocpol and Somers 1980:Fig. 2) where theory may be applied in a top-down method, developed in a bottom-up process, or generalized within certain scope conditions. This remains an excellent way to think of the purposes of comparative analysis-different types of comparison suit different types of analysis and thus generate different types of knowledge.

Skocpol and Somers' (1980) account implies different comparative configurations of cases. I thus argue that comparison can be thought of in network terms. Cases can be conceived of as nodes and the comparisons between cases as ties between two nodes. Each mode of comparative history therefore would result in a different type of network. To illustrate, imagine three cases that have all been compared to each other in a single study. The network structure is the same no matter the mode of investigation-a triad of three nodes and three ties. But what comprises the network structure will differ. In parallel demonstration of theory, the cases are diverse, coming from various times, places, and even types. In contrast of contexts, the cases are more similar, sharing a time or a place. Finally, in macro-causal analysis, there is some variation among cases but they are bounded in a legible and logical fashion along the lines of familial types. Thus, what method of analysis is employed for a study could be understood by considering its network of comparison alone, even without reading the text.

But epistemologies do not come from a single, however influential, study of a phenomenon. Rather, they are the accumulation of knowledge in an entire field. Thus, the epistemic positions of a comparative field can be determined by considering its structure of 
comparison as a whole. Figure 1 provides idealized sketches of the possibilities. In the first network (Figure 1a), comparison is evenly spread throughout the universe of ten cases; all cases have been compared to all other cases. This network is akin to parallel demonstration of theory, and portable knowledge would likely accumulate. For the second network (Figure 1b), cases are compared to each other in isolated clusters. Grounded knowledge is the likeliest result as comparison has not been made portable to other contexts with bridging ties between clusters. Finally, in Figure 1c, there is a mix of the two previous ideal types-some clustering in comparison occurs, but clusters are linked to each other. This suggests a balance between portability and groundedness as in macro-causal analysis.

I argue that these networks of comparison, for a comparative field as a whole, precede the accumulation of knowledge and the development of an epistemology. As cases are linked, or not, to each other through strong and weak ties, different configurations develop. This network structure affects the likelihood that a given epistemological position would have the empirical support to develop, as Skocpol and Somers (1980) argue. The preceding structure of comparison thus points the way to subsequent theory generation. Metaphorically speaking, if Skocpol had not written States and Social Revolutions or McAdam, Tarrow, and Tilly had not published Dynamics of Contention then we would have had to invent them.

Below, I examine the evidence for which structure of comparison dominates the study of revolution using two sets of analyses: investigating cases and comparisons in the network overall; and over time analyses that confirm that comparison precedes epistemology.

\section{Data on Revolutionary Cases and Comparative Networks}

The data for this study are a near complete sample of social scientific studies of revolution that use the case comparative method published in English between 1970 and 2009. Peer-reviewed articles and books listed in three central social science databases (Sociological Abstracts, Worldwide Political Science Abstracts, and PAIS International) and one general database (Books in Print) are searched using subject headings with wildcard variants of the keyword "revolution". ${ }^{1}$ This method yields 6,621 entries from 1970 to 2009 (though in the case of Books in Print not necessarily unique works as reprints are counted, as well). In addition, the results are verified using two annotated bibliographies to check for

\footnotetext{
1 The initial searches were completed in summer of 2010. As indexing, particularly for recent publications, can change, the searches and sources were reexamined in fall of 2012. As the first full decade in all of the databases is the 1970s, I begin there and then end with the last full decade of the 2000s. Keyword synonyms for revolution, such as uprising, are not included as the issue is about the self-conscious field of revolution studies rather than all information available about revolutions.
} 
missing studies_-Goodwin's (2001) appendix and Tilly's personal bibliography made public by Christian Davenport after his passing in $2008 .^{2}$

From these lists, comparative case studies are identified for inclusion in the dataset using two criteria. First, the study must examine at least two or more cases (whether actual historic events or negative cases), per the author of the study's own treatment of what constitutes a case. ${ }^{3}$ Second, the strategy of analysis must be comparative, again relying on the author's own assessment of their methodology. In the absence of explicit claims of comparative method (which occurs in a notable minority of studies, see Beck (2017b)), two or more cases that are given roughly equal treatment are considered comparative. These criteria encompass works that employ multiple analytical strategies; for instance, Paige's study of agrarian revolution includes both case comparisons and basic statistical tests, and is included in the dataset.

The method of identification yields a sample of 148 comparative case studies, ranging from small $\mathrm{N}$ studies, as in Skocpol's (1979) famous analysis, to medium N studies that use methods like qualitative comparative analysis, as in Foran's (2005) survey of third world revolutions. The studies found cover 203 different revolutionary events that have been studied multiple times, yielding 639 cases. The cases are from 96 countries or regions occurring as early as the $3^{\text {rd }}$ century BCE to as recently as 2005 , including successful revolutions, failed or ongoing revolutionary situations, and negative cases where revolutionary contention did not occur.

While the sampling strategy attempts to identify the entire population of studies that use the case comparative method, there are possible limitations and biases. First, it is worth noting that the selection strategy does not capture studies of single revolutions nor does it include the (few) solely statistical studies of revolution. It also excludes comparisons that are made in passing as implications or contrasts, which leaves aside the voluminous literate on revolutions in humanistic fields like history, as well as general surveys, theoretical treatises, and other works with non-empirical goals. ${ }^{4}$ Consequently, the data do not account for the turn in historical sociology towards a framing of "in comparative perspective" employed by studies that primarily focus on a single case. As such, the sample best represents a methodthe increasingly formalized case comparison (see George and Bennett 2005; Gerring 2007; Goertz and Mahoney 2012). Yet, notably, the social science of revolution predominantly

${ }^{2}$ Charles Tilly, 2005, "Selected Readings on States and Relations Among States." Retrieved from http://www.cdavenport.com/, December 2008.

3 In a few instances, the need to consolidate cases into network nodes necessitates putting co-occurring events into conglomerates that are usually considered as one case in the literature, e.g. the second civil war and 1980s coup d'états in Sudan.

${ }^{4}$ While explicit reprints of studies are not included, it is common that a comparative analysis will be published in both article format and as a part of a larger book project. As the unit of analysis is the study and not the scholar, these multiple instances are included - the logic being that the analysis passed the muster of peer-review twice and was allowed as separate publications by different editors. 
relies on case comparison to develop its theories (Goldstone 2003), even as it is only one form of historical sociology (Steinmetz 2004). This suggests that comparative case studies are a good representation of knowledge in the field more broadly. There is also an analytical choice made here: focusing on comparison allows for an investigation of the relationship between multiple studies' empirical bases and how they generate an epistemology.

Second, the sample only covers works published in English. It is possible that nonEnglish language studies have different patterns. However, given the lingua anglo of contemporary social science, it is an acceptable boundary to the sample. It is also reasonable to suspect that non-English sources in regional publications would focus on local events, which would only magnify the patterns I discuss below. As with any sample, the absence of a study or two is unlikely to change the overall patterns of epistemology described below.

\section{Case Attributes}

Six characteristics of the cases identified are coded from the studies found and secondary sources. First is the era of a case, in world-historical terms, determined by the year of the case's onset. ${ }^{5}$ Next, the geographic location of a case is coded by region. For the few cases that are multi-regional events, they are coded as such. Third, while revolutions are complex events, it is possible to identify their primary mode of contention to help distinguish between types of revolution (e.g., Stephan and Chenoweth 2008). Six different types of contention are identified, differentiating between those conducted through organized violence, mobilization more typical of social movement repertoires, revolutions from above, and inter-state or cross-border conflicts. Given the presence of negative cases in the sample and the complexity of some cases, these each are categorized separately. Another attribute of a revolution that distinguishes its type is its ideological character. While ideology is often dynamic and emergent in revolutionary situations, the popular understanding of revolutions settles in their aftermath, allowing for such an appraisal (Parker 1999). The primary ideological basis of the challengers is coded in seven categories-leftist, democratic, national-separatist, religious, and reactionary, with separate categories for complex cases and negative cases. Finally, the outcome of a revolutionary case is coded in an ordered fashion: social revolutions that change both regime and society (per Skocpol's (1979) definition and Goodwin's [2001] and Foran's (2005) determinations); political revolutions that change a regime or governance structure but do not lead to lasting social change (see Goldstone 1991); and cases of failure or ongoing contention (which approximates Tilly's (1993) definition of a revolutionary situation as effective, incompatible dual claims to sovereignty). As with the other attributes, categories for negative cases and other outcomes are included.

${ }^{5}$ For those cases that cover a general period of time, e.g., the 17th century Ottoman crisis (Goldstone 1991), onset is set to the first year, e.g. 1600 . 
Table 1 summarizes the sample overall and the distribution of attributes for the 639 comparative cases.

[Table 1 here]

\section{Constructing Network Data}

Cases' joint appearance in the same study is used to construct one-mode network data where a unique case is the node and a comparison is the tie. For example, a study with two cases would yield one reciprocal dyad, a study with three cases would yield one triad, and so on. Where cases appear in multiple studies, studies' case comparisons are linked to each other through strong and weak ties. Figure 2 presents the resulting network of 203 nodes encompassing 1,756 dyads, composed of a main core and six isolated sets of relationships. The overall sum of ties (i.e. joint appearance in one or more studies) is 5,278, with maximum tie strength of 20 , and the overall network density is .129 . The disconnected subgraphs (which are discussed in more detail later) represent individual studies, such as Katz's (1997) study of revolutionary waves, or distinct sub-literatures, such as the study of the postcommunist Colour Revolutions in Eastern Europe.

[Figure 2 here]

These data are analyzed in two different ways. First, I examine the comparative network as a whole, investigating which cases are the most popular for study, which attributes of cases are most common, and what type of knowledge might result. Second, I consider the change over time in cases and the structure of comparison to show that the practice of case comparison precedes the development of the revolution field's epistemologies. Finally, I discuss an implication of this work-to what extent casing and comparison represents the actual universe of revolutionary events.

\section{The Structure of Comparison, 1970-2009}

This section explores the nature of cases and structure of comparison overall in case comparative study of revolution since 1970. I begin by presenting which cases are most preferred for study. Second, I examine the network of case comparisons to reveal what type of empirical knowledge is most likely to be generated. I investigate clustering in the network to establish its commonality and determine what composes clusters. Then I examine homophily in dyadic comparison to see the patterns in the juxtaposition of cases. The results suggest considerable homophily in comparison and clusters, especially by geography and era, which is most amenable to a relatively grounded epistemology.

It is no secret that particular revolutions are particularly popular, returned to by scholars numerous times. These cases might be especially fertile for analysis or represent prototypes to which other cases are compared (Gerring 2007; Goertz and Mahoney 2012), and could even be considered a "model organism" for the social science of revolution 
(Guggenheim and Krause 2012). What is surprising, however, is which events are the most popular. Table 2 presents the cases that have been studied ten or more times in the past forty years. The Nicaraguan Revolution of 1979 is the most common case, having been studied 39 different times making up $6 \%$ of all cases by itself. The second most popular case is another Latin American socialist revolution-Cuba in 1959. It is not until the third and fourth places that classic cases rank, the Russian Revolution of 1917 and France in 1789. The pattern is repeated across the most popular events- the Salvadoran Civil War is almost as popular as the more historically notable Islamic Revolution in Iran, and mid-20 th revolutionary situations in Guatemala and Bolivia outpace the English Civil War and Glorious Revolution of the $17^{\text {th }}$ century. Overall, popular revolutions for study seem to be either Latin American or classic cases.

[Table 2 here]

Altogether the dozen most popular cases are 39\% of all units of analysis (meaning that 191 other cases make up the remaining 60\%), and are far above the mean popularity of 3.2. The picture is much the same in network terms. Each of the most studied cases ranks quite high in normalized valued degree centrality - the number of cases that have been compared to a particular node—and altogether hold a $27 \%$ share of network ties. Not surprisingly, valued degree centrality correlates highly with the frequency of a case's study ( $\beta=.801, p<.001)$. This is not a pattern that a historiography of revolution might expect. World historically important events, such as the great revolutions of 1848 in Europe or the collapse of communism of 1989, do not make the list at all. And seemingly historically trivial cases, like the Bolivian Revolution of 1952, are popular.

But what of comparisons between cases? As previously argued, comparisons that generate portable knowledge tend to be made between cases that cross temporal and spatial bounds. If comparison crosses type families of cases, then a parallel demonstration of theory epistemology could result. Accordingly, we would expect such a network to be fairly cohesive, with limited isolates and clusters, creating the potential for portable theoretical inferences. On the other hand, comparisons that generate grounded knowledge, a contrast of contexts epistemology, tend to fall with spatial and temporal boundaries. A network of this sort would be more fragmented and have clusters determined by era and place. In between the two poles, is historically bounded knowledge that is portable to other contexts, as in macro-causal analysis. While clustering in the network occurs here, they are legible as distinct sets of cases and there would be dense connections between clusters.

The entire comparative network, as presented in Figure 2, has clear clustering, several isolates, and a number of pendants. Pendants form when relatively understudied cases are compared to a relatively more popular one, and isolates are the result of no bridging ties. Clearly, comparison is not evenly distributed among the cases studied. A metatheoretical position of the complete portability of theories of revolution is thus less likely to 
develop from revolution studies as a whole. But clustering can lend itself to grounded or portable knowledge, depending on which comparisons comprise clusters. I thus examine clustering in more detail using the Louvain community detection algorithm as implemented in Pajek. This procedure identifies the sets of cases that are more connected to each other than other nodes, and allows the boundaries of clusters to be seen. The algorithm identifies 12 distinct communities in the network overall. 6 Table 3 presents information about these clusters that are represented by colors in Figure 2: their size, density, and a measure of homophily between nodes, the E-I Index, which compares in-group ties to out-group ties to determine how homophilous a cluster is on a scale of -1 to 1 . Smaller E-I scores indicate greater homophily.

\section{[Table 3 here]}

Of the 12 clusters, five are disconnected subgraphs and all but one of these are exclusively made up of one study that has events not studied elsewhere (clusters $h, i, j, k$, and $l$ in Table 3). The remaining clusters tell us more about the structure of comparison. The two largest clusters, $a$ and $b$, seem to represent $20^{\text {th }}$ century semi-peripheral revolutions (53 nodes) and classic great revolutions (50 nodes) respectively, and cover about half of the unique cases studied overall. The third largest community $c$, with 34 cases, is primarily Latin American revolutions. Cluster $d$ focuses on the mostly nonviolent or pacted transitions of the 1980s and early 1990s, and cluster $e$ is the disconnected subgraph of the Colour Revolutions literature. Finally, clusters $f$ and $g$ appear to be small sets of studies focused on military revolutions and mid-20 th century resistance to communism.

The densest and most intra-connected cluster is that of the Latin American revolutions (cluster $c$ ), which means that numerous studies have used comparisons within this region alone. Of the other large clusters, the great revolutions community (cluster $b$ ) is less dense, but has relatively high homophily (given by the E-I index score of -.591). Therefore, the great, social revolutions are not studied as frequently as some other clusters and tend to be compared to one another. Similarly, semi-peripheral revolutions (cluster $d$ ) and Latin American revolutions are relatively homophilous. These results, and the perfectly homophilous Colour Revolutions cluster $(e)$, suggest that clusters form along the lines of region and era primarily, and only secondarily along the lines of type of case. There is little evidence that clusters are the result of cross-typological comparisons that would create perfectly portable knowledge. Rather, the clustering that occurs is most likely to produce grounded knowledge within sets of similar cases.

To assess this pattern further, I consider which comparisons are most frequently drawn. Table 4 presents the most common dyads within the entire network. The Nicaraguan Revolution as compared to the Cuban Revolution is the most common comparison. In close

${ }^{6}$ The best fitting resolution parameter is .75 as Cramer's $\mathrm{V}$ is 1.00 , showing a perfect correlation between different iterations. 
second place, is comparison of the Russian Revolution to the French Revolution. Comparison between Latin American cases makes up half of the ten most frequent dyads, and not a single top ten comparison breaks either era, geographic, or familial type boundaries.

[Table 4 here]

This impression is supported by analyses using quadratic assignment procedures. QAP correlation compares random permutations of dyadic ties in the network to the observed ties to generate estimates of statistical significance based on attributes of the node. In other words, it allows us to see if cases that share similar attributes are more or less likely to be compared to one another than chance alone would dictate. I employ the coding of case attributes detailed previously as a measure of homophily. Thus, the variables are dyads that share the same era, region, mode of contention, ideological basis, or outcome. Table 5 reports the results of QAP correlation of the homophily between cases.

\section{[Table 5 here]}

As $52 \%$ of cases are only studied once, it is not surprising that there is no significant correlation between case attributes and the likelihood of comparison for the entire network. Key to my argument is that comparison in the field as a whole generates epistemologies, not individual studies. Thus, I also calculate QAP correlations for cases that have been compared more than once, which indicates some consensus about how these cases can be employed. Here, there is significant homophily across all characteristics. The strongest correlation is for cases that share the same time period, with the same region the second strongest. Positive correlation among mode, ideology, and outcome are also statistically significant yet with weaker effects. The correlation for these latter attributes may be weaker because of the use of negative cases (17\% of all unique cases), which are coded as not sharing the attribute of others. In other words, there is a high degree of homophily in comparison, and it is most likely to occur because of temporal-spatial boundaries first, and familial types second. ${ }^{7}$

In sum, analyses of the overall structure of cases and comparison in the comparative study of revolution point to the same conclusion. Casing seems to be driven by a particular image of what constitutes a revolution or, at least, a revolution worth studying. And this image is not that of a great, classic revolution like France in 1789, but of a more modern form-the leftist, insurgent social revolution. The form is historically bounded, occurring primarily in the post-World War II era, and certainly reached one of its apogees in Latin America which might explain that region's prevalence as scholars seek to control for time and space in their comparisons. Accordingly, comparison tends to cluster most strongly along temporal and spatial boundaries or, secondarily, within familial types of revolutions.

7 The results of QAP regression, where the strength of a tie (i.e., how many times the two cases have been compared) is predicted by homphily, confirms that cases with similar regions, eras, and outcomes are more likely to be compared repeatedly. 
Similarity in time and space also most strongly predicts dyadic comparison, and case comparisons of similar events predominate in general. This makes sense, in that scholars often try to control for time and space in their comparative design. But this has an implication for the knowledge that can develop.

There does not appear to an empirical foundation that would generate an epistemology of entirely portable knowledge as in the parallel demonstration of theory mode of analysis. As some comparisons are made within families of cases, the comparative study of revolution as a whole can generate a degree of portable macro-causal knowledge. But since most cases and comparisons fall within temporal and spatial boundaries, the epistemological position which is most likely to result is that of grounded knowledge, as in contrast of contexts. In short, the structure of comparison in the social science of revolution is best positioned to produce historically-bounded knowledge and support an epistemology that prefers groundedness to portability.

Yet different epistemologies have dominated the field at different times, as previously described. The key argument of this paper is that the empirical basis of the field predates the development of an understanding of what revolution is in general. I present the evidence for this argument in the next section.

\section{Cases and Comparisons over Time}

If the empirical basis of a comparative field affects the sort of knowledge that can be had, then analysis of the change in the structure of comparison over time should show that an empirical configuration precedes the development of an epistemology of revolution. In this section, I present over time analyses in a fashion parallel to the preceding section: examination of popular cases and comparisons, followed by analysis of the comparative network. As described previously, the recent epistemologies of revolution theory have had two key time points. An epistemology of portable causes of revolution emerged in the late 1970s and lasted primarily through the 1980s, and an epistemology of grounded knowledge emerged in the mid-1990s and persisted throughout the 2000s. I thus use the decade as the primary unit of time to investigate the patterns. While the number of studies in each decade varies, from as few as 24 in the 1970s to a highpoint of 54 in the 1990s, the average number of cases in each study is fairly constant around four (see Table 1). Thus, changes in comparative methods (see Mahoney 2004; Ragin 2008) have not much affected the number of cases employed by scholars.

Table 6 presents the five most popular revolutionary cases for study by decade. Even before considering which cases are popular, there is a notable pattern in how many rank among the most frequently studied. In the 1970s, there was a clear top five with no ties for a rank but by the 2000s five cases tie for the fourth most popular. This suggests a growing fragmentation in which cases are emphasized. The top five list also changes 
substantially from decade to decade. In the 1970s, the focus was on classic cases of revolution-Russia in 1917, China in 1911, and Japan in 1867-with a couple of Marxist insurgencies, Cuba and Vietnam, also popular. Interestingly, a majority of these are clear cases of leftist movements. But these cases do not remain as popular over time. By the 1980s, Latin American events begin to dominate-Nicaragua in 1979 emerges as the most popular case and remains so through 2009. Cuba maintains its popularity and other Latin American cases appear, such as El Salvador. In the 2000s, the Colour Revolutions of Ukraine, Georgia, and Serbia emerge as another focus. This suggests that the recency of a case may influence its popularity, and that the field grows through the incorporation of new events rather than repeated examination of a consensually defined terrain.

\section{[Table 6 here]}

Yet recency alone is not enough to explain popularity as the example of Iran in 1979 demonstrates. ${ }^{8}$ While recent and popular in the 1980s, it never receives the attention of Nicaragua in subsequent decades. And the collapse of communism in 1989, either as a global event or individual country cases, never rises to among the most popular. In fact, all the cases beginning in 1989 have only been studied 19 times overall, far less than the Nicaraguan Revolution, and still less than events of the similarly momentous year 1946 which have been studied 39 times.

As previously noted, Table 1 presents changes over time in scholarly focus. In the 1970s and 1980s, social revolutions are associated with greater popularity. By the 1990s, however, taking place in Latin America and leftist mobilizations also result in more casing, and, in the 2000s, insurgencies fall out of favor as a focus on nonviolent revolutions like the Colour Revolutions emerges. Supplementary regression analyses support this interpretation. ${ }^{9}$ Only the outcome of social revolution consistently predicts popularity across the decades. Leftist cases do, as well, predict popularity in the 1990s and 2000s. Overall, this suggests that social revolutions are the most popular for study no matter the decade, and that an increasing number of other factors are significantly associated with popularity as the decades pass. In short, more and different cases become popular and their popularity is driven by more and different characteristics than in previous decades. By the 2000s, there is increasing fragmentation in the field. And a fragmented field of study is not well suited to develop portable explanations of revolutions. Grounded knowledge is the logical result.

Change in the structure of comparison also supports this interpretation. Figure 3 presents the network of case comparisons for each decade. There is a visible fragmentation of the field over time. In the 1970s, the network shows only a few clusters that are not particularly more dense than the network as a whole, suggesting that they are not strongly bounded comparisons. In the 1980s, pendants increase and the clusters grow in density. By

${ }^{8}$ Regression of popularity on the year of onset also shows no statistically significant relationship.

${ }^{9}$ Results available from the author upon request. 
the 1990s, a network that looks like the overall structure of comparison emerges and persists throughout the 2000s: several isolates, increasing numbers of pendants, and clusters that are more tightly drawn. Over time, the density of the network overall decreases slightly, while the average number of ties increases. In other words, the number of comparisons rise, like the number of cases considered, but they increasingly take place within particular clusters.

[Figure 3 here]

This is borne out by Louvain community detection for each decade's network. In the 1970s (Figure 3a), five clusters are detected and are all legible as family types: Third World leftist revolutions like the Chinese Civil War, Cuban Revolution, and Mexican Revolution of 1910 (cluster a); semi-peripheral revolutions from above like the Young Turks and Egypt in 1952 (cluster b); the classic, great revolutions (cluster c); anti-colonial insurgencies like that of the Mau Mau and Irish Republican Army (cluster d); and, finally, 1960s decolonization cases such as in the Portuguese colonies and Vietnam (cluster $e$ ). In the 1980s (Figure 3b), there are nine clusters, and, in the 1990s (Figure 3c), ten clusters are detected. By the 2000s (Figure 3d), 13 communities are detected. Notably, these clusters become less legible as types of revolutions, in contrast to the 1970s, and display greater spatial and temporal bounding. For instance, the 1980s network in Figure $3 \mathrm{~b}$ includes two Latin American clusters ( $a$ and $d$ ). In the 1990s (Figure 3c), clusters are formed from regions like Latin America (cluster $b$ ) and Eastern Europe (clusters $c$ and $f$ ), but also from $20^{\text {th }}$ century Cold War events (clusters e). And in the 2000s (Figure 3d), there are even fewer legible clusters and an increasing number of isolates. The only cluster of the main core that is identifiable is a great revolutions cluster (cluster b)..$^{10}$

More tellingly, homophily in dyadic comparison also changes over time. Table 7 presents the most common dyadic comparisons by decade. In the 1970s, classic cases of revolution predominate, with the Russian Revolution as compared to China's Revolution of 1911 being the most popular. The pattern switches in the 1980s, as Latin American cases receive more attention. By the 1990s, only one popular dyad involves non-Latin American cases - the classic comparison of the Russian Revolution to the French Revolution. In the 2000s, Latin American comparisons are still popular, but comparisons of the recent Colour Revolutions emerge. What matters here is the pattern of homophilous comparison. Popular dyads tend to share times and geographies, with family type making a few appearances.

QAP correlations by decade confirm this trend (see Table 8). While for each decade similarity among cases correlates to the likelihood of their comparison (except for ideology which falls out of favor in the 2000s), the strength of the correlation changes markedly. In the 1970s, ideology is the strongest correlate of comparison but still has only relatively weak influence. By the 1980s, however, region and time emerge as significant correlations with

${ }^{10}$ Full numeric descriptions of clusters are available from the author upon request. 
much greater effect. This is most pronounced in the 1990s and then lessens in the 2000s, which is when the other analyses indicate the study of revolution becomes less cohesive. In short, homophily in comparison, particularly for region and era, tends to increase over time until fragmentation sets in.

[Table 8 here]

These results all substantiate the key argument of this paper-the structure of comparison in revolution studies predates the epistemologies of the field, and, in fact, may create them. For example, take the study of revolution in the 1970s. Here, what a revolution actually is is fairly well understood-revolutions are great social revolutions. Accordingly, comparison takes place somewhat evenly among the cases considered, and when clustering occurs it is within historically bounded familial types rather than within temporal or spatial boundaries. This structure of comparison is amendable to an epistemic mixture of macrocausal analysis and parallel demonstration of theory. My argument expects such an empirical basis to generate portable knowledge. This is exactly what happens in 1979, when Skocpol publishes States and Social Revolutions. Her work advocates a macro-causal framework for understanding revolution — state breakdown theory — which has portable implications for cases beyond her initial scope conditions (see Skocpol 1982, 1994). If Skocpol had not published a macro-causal analysis, then someone else would have. The structure of comparison clearly pointed to it.

Contrast this to the situation of the mid-1990s when an epistemology of the inherent uniqueness of every revolution and mechanistic perspectives began to emerge. Beforehand, at the turn of the 1980s, new events like Nicaragua took place and quickly dominated casing. More and different events were incorporated into study over time and popularity began to be less centered on just a few classic cases. This could have been good news for the generation of portable theories applicable to many different cases, but the structure of comparison became more and more driven by homophily. Further, comparisons of the 1980s and throughout the 1990s moved away from the macro-causal approach of familial types and towards contrast of context region- and era-bounded examinations. Thus, my theory anticipates that this comparative field would generate an increasingly grounded epistemic position about revolution, which is, in fact, what resulted. If the effect went in the other direction - a general understanding of revolution creates the structure of comparison - then we would expect to see the empirical traces of portable epistemologies in the 1980s and a structure of grounded epistemologies appear in the later 2000s. This is not the case. Comparison precedes epistemology.

\section{Representing the Universe of Revolutions}

If the epistemology of a field is based on which cases it considers, the question is raised as to how well the cases examined capture the universe of cases that actually exists. 
Perhaps revolution in general tends to a particular form, and thus the time, space, and type bounding identified above creates no issue for developing knowledge about revolution broadly. Alternatively, perhaps, historical bounding has created selection bias as other variants of revolution have not been investigated as fully.

To answer this puzzle is quite difficult. It requires knowing what the universe of revolutions actually looks like, and comparing what has been studied to what could be studied. In the absence of a near complete and consensual database of revolutionary events, definitive conclusions cannot be drawn. Yet inferences can still be made. I turn to a list of revolutionary events that is independent of the cases identified by this study: Charles Tilly's (1993) event catalogue of revolutionary situations that occurred in six different regions of Europe between 1492 and 1992.

I make the contrast as fair as possible. First, from the sample of comparative revolution studies, I only include events that took place in Europe within the regions that Tilly considered: the French states, the British Isles, the Low Countries, the Iberian Peninsula, the Balkans and Hungary, and the Russian states. Second, given that some have argued revolution is a modern phenomenon (Goodwin 2001), I limit the comparison to events of both lists that occurred from 1789 to 1992. This accounts for the possibility that some scholars would not count the diversity of early modern events in Tilly's catalogue, including civil wars and religious conflicts, as revolutionary (see Beck 2011). The resulting lists are summarized by their attributes in Table 9 .

\section{[Table 9 here]}

From 1789 to 1992, Tilly identifies 113 distinct revolutionary situations, while the comparative studies list I collected includes only 39 unique cases. The two lists have 24 cases in common, which is $62 \%$ of the events in the comparative studies but merely $21 \%$ of Tilly's catalogue. Notably, the comparative studies' cases do not seem to represent the "universe" of Tilly. The mean start year is much later for comparative studies, 1925, than Tilly, 1877. Comparative studies' cases predominately take place in Eastern Europe and Russia, while Tilly identified many more events on the Iberian Peninsula. Modes of contention and ideological bases differ substantially, as well. A majority of the comparative studies' cases have a mass uprising mode of contention and Tilly's list has a plurality of insurgent forms of contention. Revolutions from above also are much more common in Tilly than comparative studies. The ideological basis of revolutionary situations in Tilly tends to be nationalistseparatist or democratic, while comparative studies prefer democratic or leftist cases and discount reactionary contention. Finally, both lists agree that failure is the most common outcome, but comparative studies prefer social revolutions to Tilly's emphasis on regime change through political revolutions.

If we take Tilly's catalogue to be more exhaustive, due not only to its size but also its focus and cataloguer's skill, then we must conclude that comparative studies do a poor 
job of replicating the actual universe of revolution. This suggests that the accumulated knowledge of the comparative study of revolution, no matter its theoretical portability or groundedness, may have problems. Most of the knowledge garnered is on the basis of a handful of cases, and casing tends to prefer a particular type of revolution that is not reflective of the larger universe of events that have occurred. In short, casing may be limited by its historical bounds of time, place, and type. While this conclusion requires further validation, its plausibility should serve as a warning to those who claim consistent findings about how and why revolutions occur (e.g., Beck 2017a; Goldstone 2001, 2003; Goodwin 2001; Mann 2013).

\section{Conclusions}

I have argued that the meta-theoretical stance of a comparative field regarding its object of study is affected by its structure of comparison. Comparison, an inductive method, makes different types of knowledge more likely to accumulate dependent on its practice. At one extreme, it can lend itself to completely portable knowledge through the examination of many cases that are exhaustive of the phenomenon's universe, as in the parallel demonstration of theory. At the other, it can be most conducive to the development of entirely grounded knowledge where the temporal and spatial boundaries of comparison are paramount, as in the contrast of contexts. In between these two ends, lies knowledge of the sort that macro-causal analysis generates where the conclusions have implications for other cases but are, in the first place, bounded by type or history. Of course, individual studies can and do create different types of knowledge. To think otherwise would be to commit an ecological fallacy. The argument is thus at the level of a field overall and its general pattern of knowledge accumulation.

For the comparative study of revolution, all the analyses have pointed to the same conclusion. In the field overall, a certain type of revolution is most commonly studied and this is driven primarily by geography and era. Also, comparison in general is highly homophilous, strongly determined by similarities in space and time. This suggests the field of revolution has been most likely to develop knowledge that tends to be grounded, rather than portable. Changes in the structure of comparison over time suggest that empirics precede meta-theory. In the 1970s, the comparative study of revolution was well positioned to create an epistemology of the portability of findings and theories, which it had done by the 1980s. In the 1980s and 1990s, the study of revolution developed more geographically and temporally bounded comparisons that suggested an epistemology of grounded knowledge, which is exactly what emerged in the late 1990s and early 2000s. The evidence is clear-in the study of revolution, the structure of comparison has preceded general understandings of what can or should be learned from studying revolution. 
There are three possible objections to this interpretation. First, I treat each comparative study equally and do not account for a study's reception in the field. I do so for good reason. I seek here to identify what the community of scholars is actually doing, not what they are citing. Such a weighting would obscure the approach of this analysis-that meta-theoretical stances are the product of the structure of comparison as a whole. Second, given the lag time between a study's origination and publication, can thought actually be traced over time? In my view, thought is the proverbial tree falling in the woods. Until a comparative study is published, the outside observer cannot discern it. A future analysis could attempt to control for publication lag time by examining the delivery dates of related conference papers and reshaping the data accordingly. In any case, the analysis undertaken here focuses on blocks of time rather than individual years, which helps account for this issue. Third, new events might drive epistemologies as much as structure of comparison, as the recent explosion of nonviolent revolution research demonstrates (e.g., Lawson 2015; Nepstad 2011; Ritter 2015; Stephan and Chenoweth 2008). The data show that new events can change the structure of comparison. The Nicaraguan Revolution seems to bring attention to Latin America, and the Colour Revolutions bring postcommunist states into focus. But the data also show that some new events have little impact, such as the notable absence of 1989. It is also reasonable to ask why the Cuban Revolution did not make popular inroads before its comparison to Nicaragua or why the nonviolent uprisings of the 1980s_-Philippines, Burma, and Eastern Europe_-did not have such an impact before the 2000s. In short, it is not the occurrence of a revolution by itself that seems to matter here. It is how a new revolution fits with the prior structure of comparison.

A natural extension of this conclusion is to consider the structure of comparison in the 2000s and what the future holds for the study of revolution. All of the analyses point to increasing fragmentation in the last decade-there are more cases, more comparisons, and more predictors of a case's popularity. Homophily in comparison has decreased a bit, but clustering remains along temporal and spatial lines, and the number of literatures disconnected empirically from the main field has grown, e.g. studies of the Colour Revolutions. We would expect this structure of comparison to generate increasingly fragmented knowledge and an epistemology of area studies expertise to emerge. I believe this is just what is happening, even as the Arab Spring has reinvigorated the study of revolution. Many of the early accounts of the Arab Spring seem to be empirically selfreferential and seek to provide an explanation of the revolutions as a regional phenomenon or an expression of the zeitgeist (see, e.g., Beck 2014; Goldstone 2013; Lawson 2015; Lynch 2013). Only a few authors have tried to make more portable comparisons (e.g., Ritter 2015). This stands in stark contrast to the empirical reality of these events, which could easily be compared to their forerunners (and inspirers) in the Colour Revolutions, the revolutions of 1989, or any other number of historically monumental cases. "Arab Spring studies" thus may 
very well develop as a mostly isolated cluster of comparisons. In short, the field is not yet on the cusp of a reemergence of epistemology that prioritizes portable knowledge.

The second implication for studies of revolution lies in the question of whether or not there actually are causes of revolution that are generalizable. The data suggest that the social science of revolution overall has not been, and still is not, well positioned to judge between competing causal imageries. Comparative studies tend to focus on a relatively small number of cases and comparisons that fit a particular image of revolution. Most cases considered revolutionary by scholars are studied only once and most comparisons between cases have only been drawn once. A case's popularity is determined by only a few characteristics, and nor is the prevalence of certain types of cases in the literature merely a reflection of what revolutionary events have occurred. It appears that the possible universe of revolution is much more diverse than what has been studied.

Moreover, the social science of revolution has evolved increasingly in the direction of specialty fields with a less broad empirical foundation, even as more events are considered revolutionary. A field that focuses heavily on a few cases and types of comparison is likely to generate an increasing number of explanations as each study tries to carve out a unique contribution to the well-established literature on a case. Sub-literatures, which are empirically disconnected from prior studies, would thus develop. Debates would occur in relative isolation from larger empirical referents and reject comparisons across different types of cases. In such a situation, causal factors and mechanisms would proliferate, as there would be little adjudication between competing explanations, and generalizable conclusions would be difficult to identify. Knowledge accumulation would accordingly be modest. This is, in fact, what seems to have occurred. The findings here suggest that the view that there are no generalizable casual conditions of revolution actually may be an artifact of the structure of comparison rather than in the nature of the phenomenon itself. The generalizability of explanations of revolution, or lack thereof, thus remains an open question.

There are also two implications for the practice of comparative-historical sociology more broadly. Much recent work on comparative-historical methods emphasizes the logic and strategies of causal inference when using single cases and small $\mathrm{N}$ comparisons (Gerring 2007; Goertz and Mahoney 2012; Ragin 2008). Less attention is paid to how the selection of comparisons can enable and constrain different types of knowledge. Yet Skocpol and Somers (1980) knew this dilemma well. The comparative scholar should go beyond merely being explicit about her case selection strategy, and engage in explicit reflection about how the selection can influence her inductive theory development. Otherwise, it can be easy to mistake the findings of a comparative study for the truth of the phenomenon, rather than just the truth of its comparisons.

Second, comparative fields generally may inherently run the risk of theoretical and empirical fragmentation. A common strategy of causal inference is to control for alternative 
explanations by comparing cases that are most similar to each other (Gerring 2007). This strategy appears to be the primary one present in the study of revolution, as geographic and temporal homophily typify comparison. Yet such groundedness can create the conditions under which knowledge accumulation slows. One antidote is for a subfield to embrace a wider diversity of methods of inference so that its structure of comparison remains robust. Another is to self-consciously consider the role of "model systems" in knowledge accumulation (Guggenheim and Krause 2012). There could be a risk of narrowness in continual visits to single cases, especially if the case is not a seminal one, as we see in the focus on the Nicaraguan Revolution. But when compared widely and frequently, such prototypes could anchor a field and prove a testing ground for competing theories, just as Skocpol and Somers (1980) might imagine. In short, comparative-historical sociology can learn how to improve its practice from the cautionary example of the sociology of revolution over the last two decades.

This study also suggests an opportunity for sociology of science. I have documented the correspondence between the preceding structure of comparison and the sensibility of the subsequent theoretical generation. This suggests that social scientific knowledge systems may evolve somewhat different than what followers of Kuhn (1962) would have expected. Epistemological shifts here appear do not appear to come from the accrual of contradictory findings, but rather the accrual of contradictory modes of analysis. Method points to theory. Yet, the evidence here cannot tell us the mechanisms behind this pattern. For this, the social organization of the subfield, the networks of scholars, and their attributes require further investigation, in line with classic approaches (e.g., Bourdieu 2004; Latour 1987; Merton 1973). For example, it is striking that so few scholars of revolution hold positions in major research universities. This might be due to the pressures of academic hiring and career advancement. Revolution is certainly a boutique topic within the boutique subfield of comparative history. The field, in Bourdieusian terms, thus might not support anything but stagnation in knowledge accumulation. It also suggests that revolution studies is perhaps less likely to develop schools of thought that can sustain themselves across scholarly generations, from master to pupil (see Collins 2000). Networks of revolution scholars are thus likely to be limited in scope and may not be able to perform the work of theory development. Initial appraisal of scholarly networks in the study of revolution-revealed by the acknowledgements sections of books - suggests this is the case. Only a handful of researchers reciprocally acknowledge each other, and there are few master-pupil ties among the authors, particularly since the 1980s.

Further, a sociology of knowledge approach might also explain some of the quizzical patterns found in the data presented here. For instance, there is a clear preference for Nicaragua over Iran even though both occurred in 1979 as the field was revived by States and Social Revolutions. Perhaps this is due to ideological bent or an experience of activism: a 
socialist revolution might be more compelling to a scholar than a religious one. Or perhaps it is because of practical reasons. Researchers, at least in the United States where most sociology of revolution is made, are more likely to speak Spanish rather than Farsi and thus one case is more accessible than the other. There is also the surprising occlusion of the collapse of communism as an object of study. 1989 figures most prominently in studies of democratization and socio-economic transformation. It seems to have been forgotten by revolution scholars, perhaps because it does not fit with the dominant type of revolution investigated. We thus must conclude that Latin Americanists, for whatever reasons, tend to see their cases as ones of revolution, while postcommunism scholars do not. This case again suggests that world-historical importance is not the primary driver of theorization. Comparisons and the resulting epistemologies thus may be due to the nature of scholarly production rather than the nature of revolution itself.

It is likely that the explanation for why comparison precedes epistemology lies in such approaches. The idiosyncrasies and knowledge of individual researchers and the opportunities and structure of the epistemic community may help generate particular comparisons leading in turn to particular theoretical imageries at particular times. Future research should examine these possibilities more deeply than space allows for here. Such analysis could reveal the mechanisms of the relationship between epistemology and comparison identified by this study.

Overall, this study has also demonstrated the utility of considering an entire subfield to draw inferences about empiricism and theorization. The consistency of the results indicates that there are analytical advantages to conceptualizing comparative social science as a network. For other fields that focus on sets of cases, such as studies of social movements or democratization, it could be possible to adapt the approach here fruitfully. If the argument of this study holds more generally, then in those fields, too, will comparison precede epistemology. 


\section{References}

Abbott, Andrew. 2001. Chaos of Disciplines. Chicago, IL: University of Chicago Press.

Adams, Julia, Elisabeth Clemens, and Ann Shola Orloff. 2005. Remaking Modernity: Politics, History, and Sociology. Durham, NC: Duke University Press.

Austin Holmes, Amy. 2012. “There Are Weeks When Decades Happen: Structure and Strategy in the Egyptian Revolution." Mobilization: An International Quarterly 17(4):391-410.

Beck, Colin J. 2011. "The World-Cultural Origins of Revolutionary Waves Five Centuries of European Contention.” Social Science History 35(2):167-207.

Beck, Colin J. 2014. "Reflections on the Revolutionary Wave in 2011." Theory and Society 43(2):197-223.

Beck, Colin J. 2017a. "Revolutions: Robust Findings, Persistence Problems, and Promising Frontiers." Pp. 168-83 in States and Peoples in Conflict: Transformations of Conflict Studies, edited by M. Stohl, M. Lichbach, and P. Grabosky. New York, NY: Routledge.

Beck, Colin J. 2017b. "The Comparative Method in Practice: Case Selection and the Social Science of Revolution." Social Science History 41(3):533-54.

Beissinger, Mark R. 2013. "The Semblance of Democratic Revolution: Coalitions in Ukraine's Orange Revolution.” American Political Science Review 107(3):574-592.

Bourdieu, Pierre. 2004. Science of Science and Reflexivity. Chicago, IL: University of Chicago Press.

Brinton, Crane. 1938. The Anatomy of Revolution. New York, NY: Prentice-Hall.

Camic, Charles, Neil Gross, and Michèle Lamont. 2012. Social Knowledge in the Making. University of Chicago Press.

Clemens, Elisabeth S. 2007. "Toward a Historicized Sociology: Theorizing Events, Processes, and Emergence." Annual Review of Sociology 33(1):527-49.

Collier, David and James Mahoney. 1996. "Insights and Pitfalls: Selection Bias in Qualitative Research.” World Politics 49(1):56-91.

Collins, Randall. 2000. The Sociology of Philosophies: A Global Theory of Intellectual Change. Cambridge, MA: Harvard University Press.

Davies, James C. 1962. "Toward a Theory of Revolution.” American Sociological Review 27(1):5-19. 
Diani, Mario. 2011. "Networks and Internet into Perspective." Swiss Political Science Review 17(4):469-74.

Dix, Robert H. 1984. “Why Revolutions Succeed \& Fail.” Polity 16(3):423-46.

Edwards, Lyford Paterson. 1927. The Natural History of Revolution. Chicago, IL: University of Chicago Press.

Emirbayer, Mustafa. 1997. "Manifesto for a Relational Sociology.” American Journal of Sociology 103(2):281-317.

Ermakoff, Ivan. 2015. “The Structure of Contingency." American Journal of Sociology 121(1):64-125.

Foran, John. 1993. "Theories of Revolution Revisited: Toward a Fourth Generation?” Sociological Theory 11(1):1-20.

Foran, John. 2005. Taking Power: On the Origins of Third World Revolutions. New York, NY: Cambridge University Press.

Foran, John. 2014. "Global Affinities: The New Cultures of Resistance Behind the Arab Spring." Pp. 47-71 in Beyond the Arab Spring: The Evolving Ruling Bargain in the Middle East, edited by M. Kamrava. Oxford: Oxford University Press.

Foran, John and Jeff Goodwin. 1993. "Revolutionary Outcomes in Iran and Nicaragua: Coalition Fragmentation, War, and the Limits of Social Transformation." Theory and Society 22(2):209-247.

Geddes, Barbara. 1990. "How the Cases You Choose Affect the Answers You Get: Selection Bias in Comparative Politics." Political Analysis 2(1):131-150.

George, Alexander Lawrence and Andrew Bennett. 2005. Case Studies and Theory Development in the Social Sciences. Cambridge, MA: MIT Press.

Gerring, John. 2007. Case Study Research: Principles and Practices. New York, NY: Cambridge University Press.

Goertz, Gary and James Mahoney. 2012. A Tale of Two Cultures: Qualitative and Quantitative Research in the Social Sciences. Princeton, NJ: Princeton University Press.

Goldstone, Jack A. 1982. "The Comparative and Historical Study of Revolutions." Annual Review of Sociology 8(1):187-207.

Goldstone, Jack A. 1991. Revolution and Rebellion in the Early Modern World. Berkeley, CA: University of California Press. 
Goldstone, Jack A. 1998. "Initial Conditions, General Laws, Path Dependence, and Explanation in Historical Sociology." American Journal of Sociology 104(3):829-45.

Goldstone, Jack A. 2001. "Toward a Fourth Generation of Revolutionary Theory.” Annual Review of Political Science 4(1):139-87.

Goldstone, Jack A. 2003. "Comparative Historical Analysis and Knowledge Accumulation in the Study of Revolutions." Pp. 41-90 in Comparative Historical Analysis in the Social Sciences, edited by J. Mahoney and D. Rueschemeyer. New York, NY: Cambridge University Press.

Goldstone, Jack A. 2013. Bringing Regimes Back in - Explaining Success and Failure in the Middle East Revolts of 2011. Rochester, NY: Social Science Research Network. Retrieved August 21, 2013 (http://papers.ssrn.com/abstract=2283655).

Goodwin, Jeff. 2001. No Other Way Out: States and Revolutionary Movements, 1945-1991. New York, NY: Cambridge University Press.

Goodwin, Jeff. 2011. "Why We Were Surprised (Again) by the Arab Spring." Swiss Political Science Review 17(4):452-56.

Guggenheim, Michael and Monika Krause. 2012. "How Facts Travel: The Model Systems of Sociology." Poetics 40(2):101-17.

Gurr, Ted Robert. 1970. Why Men Rebel. Princeton, NJ: Princeton University Press.

Hale, Henry E. 2013. "Regime Change Cascades: What We Have Learned from the 1848 Revolutions to the 2011 Arab Uprisings." Annual Review of Political Science 16(1):33153.

Halliday, Fred. 1999. Revolution and World Politics: The Rise and Fall of the Sixth Great Power. Durham, NC: Duke University Press.

Huntington, Samuel P. 1968. Political Order in Changing Societies. New Haven, CT: Yale University Press.

Jepperson, Ronald and John W. Meyer. 2011. "Multiple Levels of Analysis and the Limitations of Methodological Individualisms*." Sociological Theory 29(1):54-73.

Katz, Mark. 1997. Revolutions and Revolutionary Waves. New York, NY: Palgrave Macmillan.

Keddie, Nikki R. 1995. Debating Revolutions. New York, NY: New York University Press.

Kuhn, Thomas S. 1962. The Structure of Scientific Revolutions. University of Chicago Press.

Kuran, Timur. 1995. "The Inevitability of Future Revolutionary Surprises.” The American Journal of Sociology 100(6):1528-51. 
Kurzman, Charles. 1996. "Structural Opportunity and Perceived Opportunity in SocialMovement Theory: The Iranian Revolution of 1979." American Sociological Review 61(1):153-70.

Kurzman, Charles. 2004. "Can Understanding Undermine Explanation? The Confused Experience of Revolution." Philosophy of the Social Sciences 34(3):328-51.

Kurzman, Charles. 2012. “The Arab Spring Uncoiled.” Mobilization: An International Quarterly 17(4):377-390.

Latour, Bruno. 1987. Science in Action: How to Follow Scientists and Engineers Through Society. Harvard University Press.

Lawson, George. 2005. Negotiated Revolutions: The Czech Republic, South Africa and Chile. Farnham: Ashgate Publishing.

Lawson, George. 2015. "Revolution, Nonviolence, and the Arab Uprisings." Mobilization: An International Quarterly 20(4):453-70.

Lawson, George. 2016. "Within and Beyond the 'Fourth Generation' of Revolutionary Theory." Sociological Theory 34(2):106-27.

Leenders, Reinoud. 2012. "Collective Action and Mobilization in Dar'a: An Anatomy of the Onset of Syria's Popular Uprising.” Mobilization: An International Quarterly 17(4):419434.

Lynch, Marc. 2013. The Arab Uprising: The Unfinished Revolutions of the New Middle East. New York, NY: PublicAffairs.

Mahoney, James. 1999. "Nominal, Ordinal, and Narrative Appraisal in Macrocausal Analysis." The American Journal of Sociology 104(4):1154-96.

Mahoney, James. 2000. "Path Dependence in Historical Sociology." Theory and Society 29(4):507-48.

Mahoney, James. 2004. “Comparative-Historical Methodology.” Annual Review of Sociology 30:81-101.

Mann, Michael. 2013. The Sources of Social Power: Volume 4, Globalizations, 1945-2011. Cambridge: Cambridge University Press.

Markoff, John. 1988. "Allies and Opponents: Nobility and Third Estate in the Spring of 1789.” American Sociological Review 53(4):477-96.

Markoff, John. 1996. Waves of Democracy: Social Movements and Political Change. Thousand Oaks, CA: Pine Forge Press. 
McAdam, Doug, Sidney Tarrow, and Charles Tilly. 2001. Dynamics of Contention. New York, NY: Cambridge University Press.

Merton, Robert K. 1973. The Sociology of Science: Theoretical and Empirical Investigations. University of Chicago Press.

Moore, Barrington. 1966. Social Origins of Dictatorship and Democracy. New York, NY: Penguin Books.

Nepstad, Sharon Erickson. 2011. Nonviolent Revolutions: Civil Resistance in the Late 20th Century. Oxford University Press.

Paige, Jeffery M. 1975. Agrarian Revolution. New York, NY: Free Press.

Parigi, Paolo and Warner Henson. n.d. "Historical Sociologists in Search of a Method."

Parker, Noel. 1999. Revolutions and History: An Essay in Interpretation. London: Wiley.

Parsa, Misagh. 2000. States, Ideologies, and Social Revolutions: A Comparative Analysis of Iran, Nicaragua, and the Philippines. New York, NY: Cambridge University Press.

Pettee, George Sawyer. 1938. The Process of Revolution. New York, NY: Harper \& Brothers.

Ragin, Charles C. 2008. Redesigning Social Inquiry: Fužy Sets and Beyond. Chicago, IL: University of Chicago Press.

Reed, Isaac Ariail. 2011. Interpretation and Social Knowledge: On the Use of Theory in the Human Sciences. Chicago, IL: University of Chicago Press.

Reed, Jean-Pierre and John Foran. 2002. "Political Cultures of Opposition: Exploring Idioms, Ideologies, and Revolutionary Agency in the Case of Nicaragua." Critical Sociology 28(3):335-70.

Ritter, Daniel. 2015. The Iron Cage of Liberalism: International Politics and Unarmed Revolutions in the Middle East and North Africa. Oxford: Oxford University Press.

Selbin, Eric. 1993. Modern Latin American Revolutions. Boulder, CO: Westview Press.

Skocpol, Theda. 1979. States and Social Revolutions. New York, NY: Cambridge University Press.

Skocpol, Theda. 1982. "Rentier State and Shi'a Islam in the Iranian Revolution." Theory and Society 11(3):265-83.

Skocpol, Theda. 1994. Social Revolutions in the Modern World. Cambridge University Press. 
Skocpol, Theda and Margaret Somers. 1980. "The Uses of Comparative History in Macrosocial Inquiry." Comparative Studies in Society and History 22(2):174-97.

Smelser, Neil J. 1962. Theory of Collective Behavior. New York, NY: Routledge \& Kegan Paul.

Snyder, David and Charles Tilly. 1972. "Hardship and Collective Violence in France, 1830 to 1960." American Sociological Review 37(5):520-32.

Sohrabi, Nader. 2002. "Global Waves, Local Actors: What the Young Turks Knew About Other Revolutions and Why It Mattered." Comparative Studies in Society and History 44(1):45-79.

Steinmetz, George. 2004. "Odious Comparisons: Incommensurability, the Case Study, and 'small N's' in Sociology." Sociological Theory 22(3):371-400.

Stephan, Maria J. and Erica Chenoweth. 2008. "Why Civil Resistance Works: The Strategic Logic of Nonviolent Conflict.” International Security 33(1):7-44.

Tilly, Charles. 1964. The Vendée. Cambridge, MA: Harvard University Press.

Tilly, Charles. 1993. European Revolutions, 1492-1992. London: Blackwell Publishers.

Tilly, Charles. 1995. "To Explain Political Processes.” The American Journal of Sociology 100(6):1594-1610.

Tilly, Charles. 2001. "Mechanisms in Political Processes." Annual Review of Political Science $4(1): 21$.

Weyland, Kurt. 2009. "The Diffusion of Revolution: '1848' in Europe and Latin America." International Organization 63(3):391-423.

Weyland, Kurt. 2012. "The Arab Spring: Why the Surprising Similarities with the Revolutionary Wave of 1848?" Perspectives on Politics 10(4):917-34.

Wolf, Eric R. 1969. Peasant Wars of the Twentieth Century. New York, NY: Harper \& Row.

Zunes, Stephen. 1994. "Unarmed Insurrections against Authoritarian Governments in the Third World: A New Kind of Revolution.” Third World Quarterly 15(3):403-26. 
FIGURE 1. Three Modes of Comparative History as Ideal-Typical Networks of 10 Cases

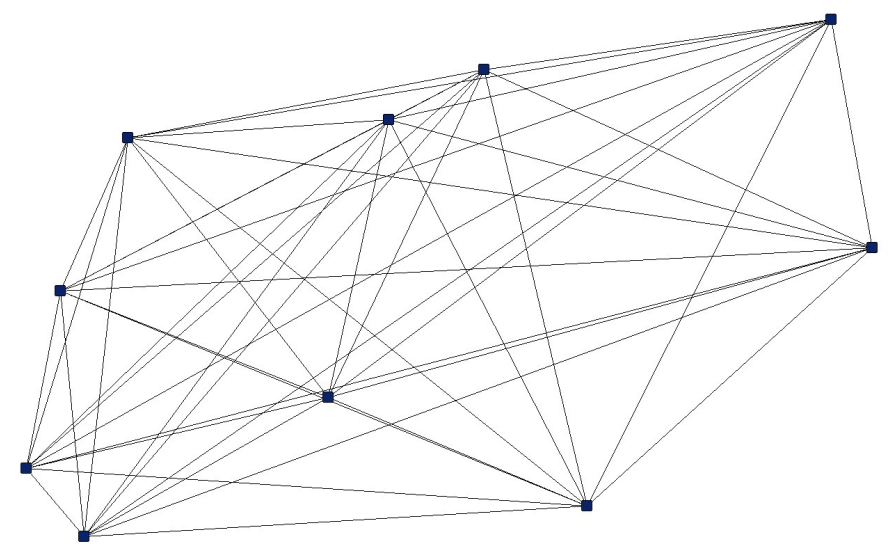

1a. Parallel Demonstration of Theory
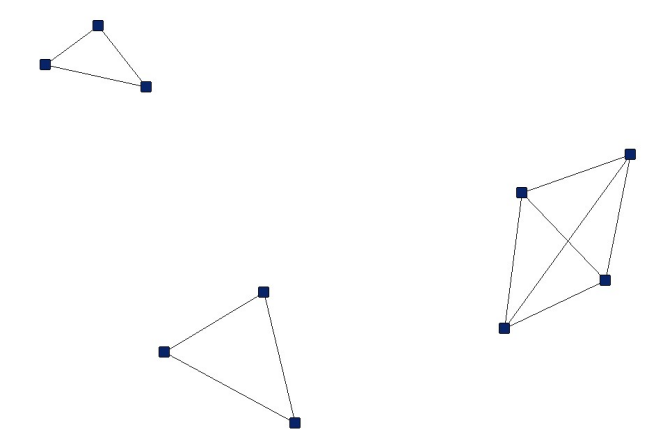

1b. Contrast of Contexts

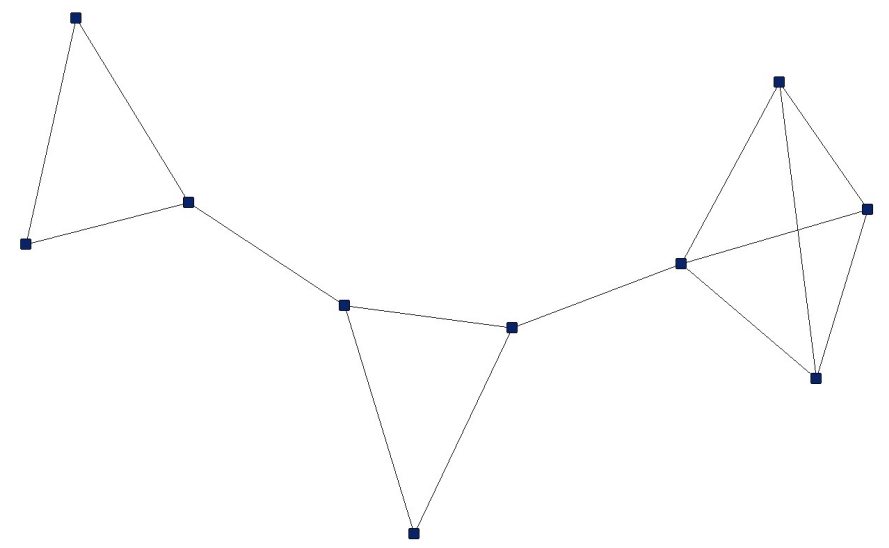

1c. Macro-Causal Analysis 
FIGURE 2. Network of Comparative Cases of Revolution, 1970-2009
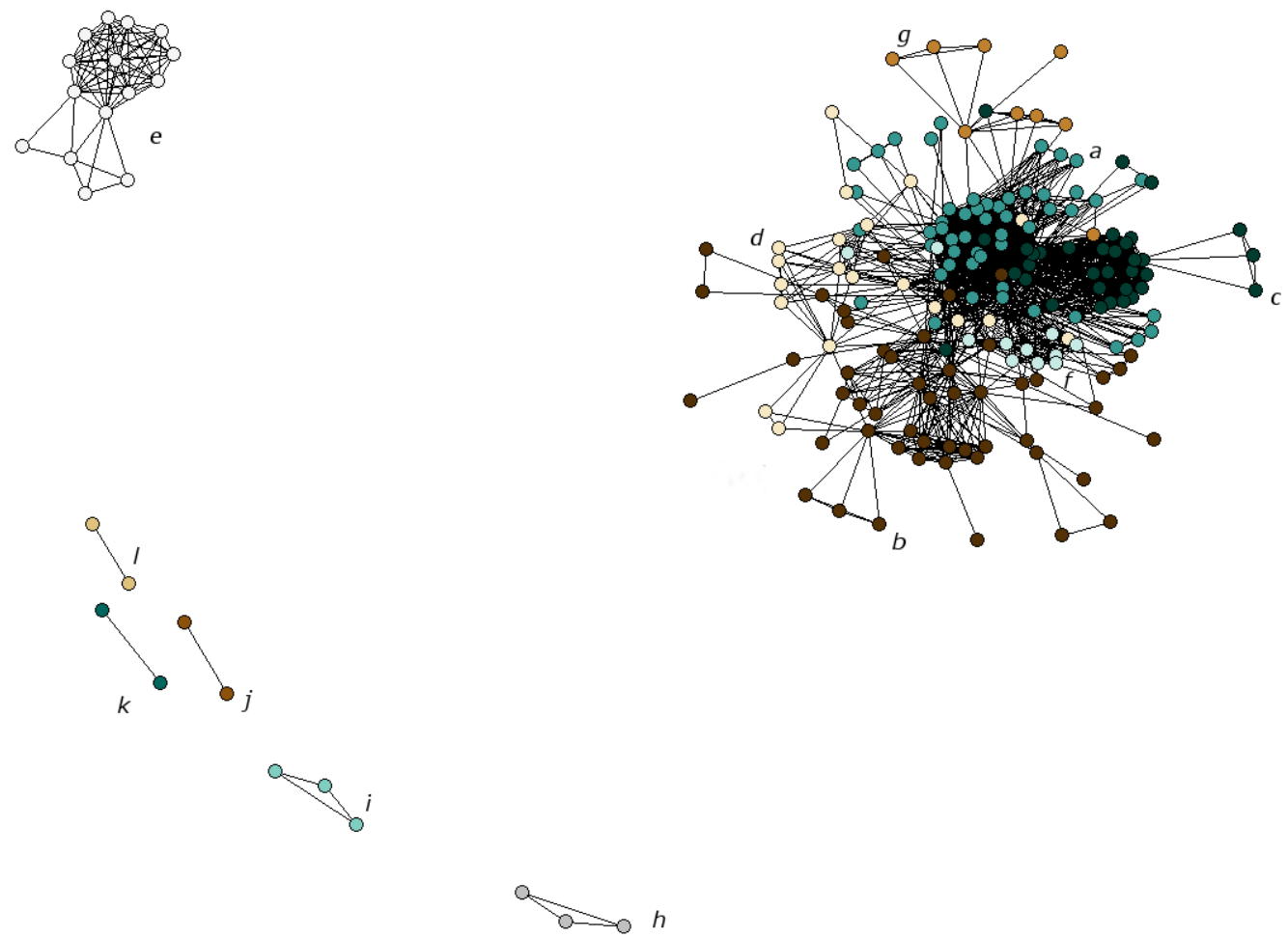
FIGURE 3. Network of Comparative Cases of Revolution by Decade

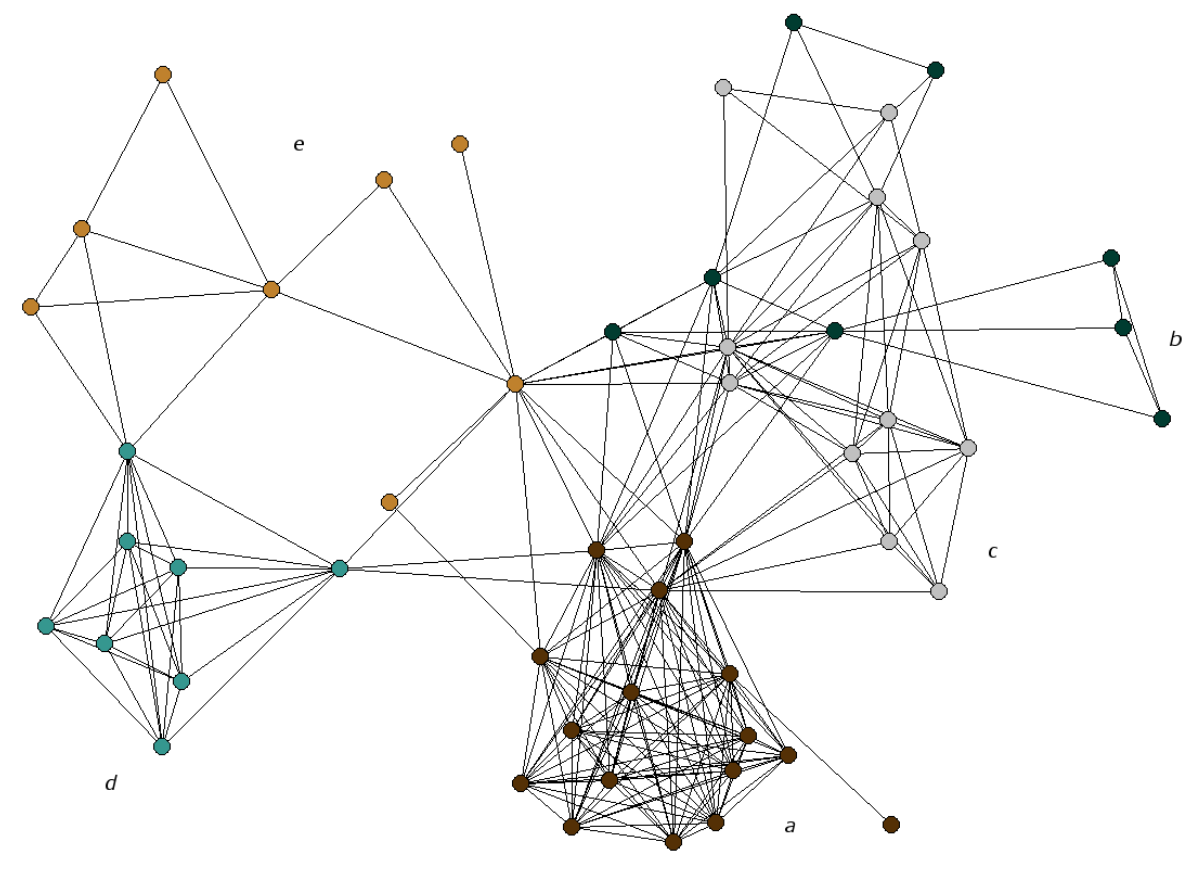

3a. 1970s

$\mathrm{N}$ of nodes: 51

Sum of ties: 528 

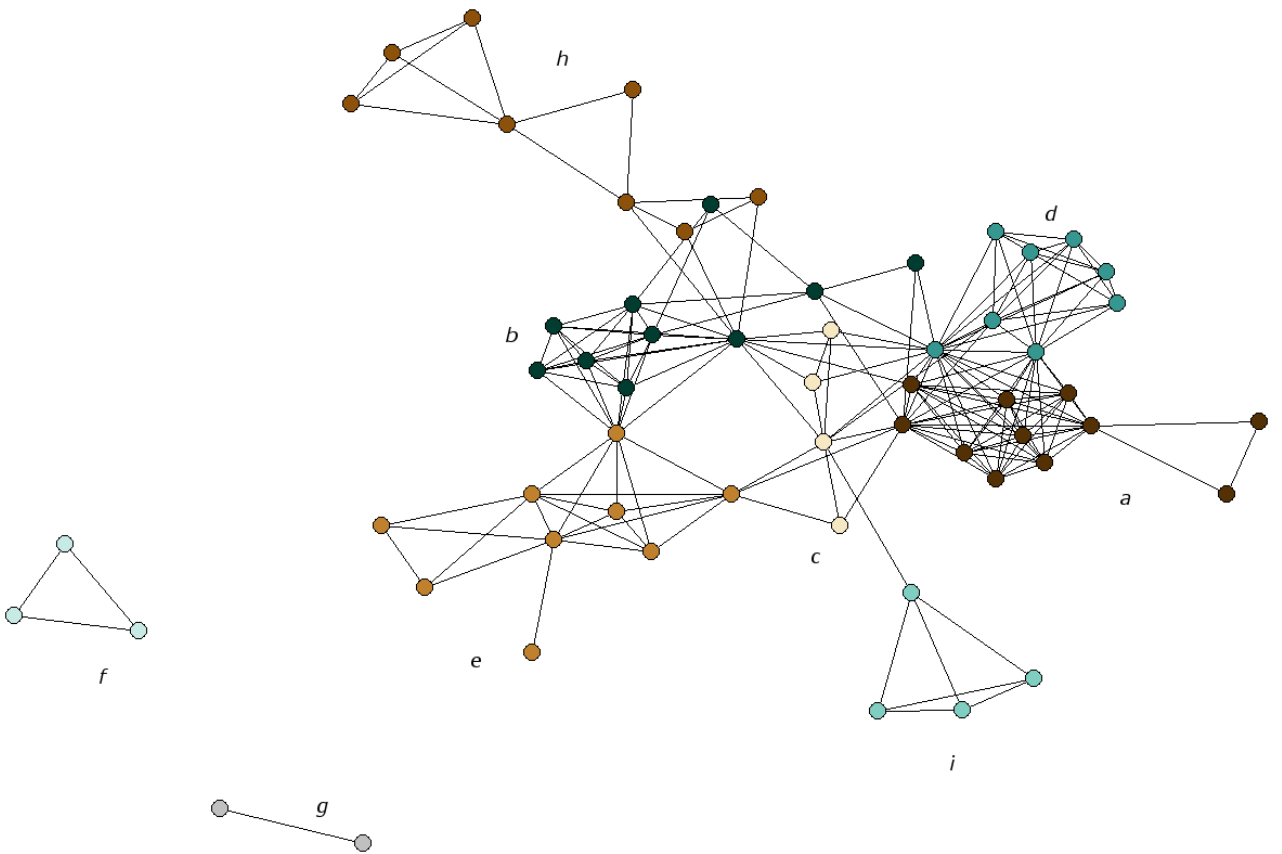

3b. 1980s

$\mathrm{N}$ of nodes: 59

Sum of ties: 434 


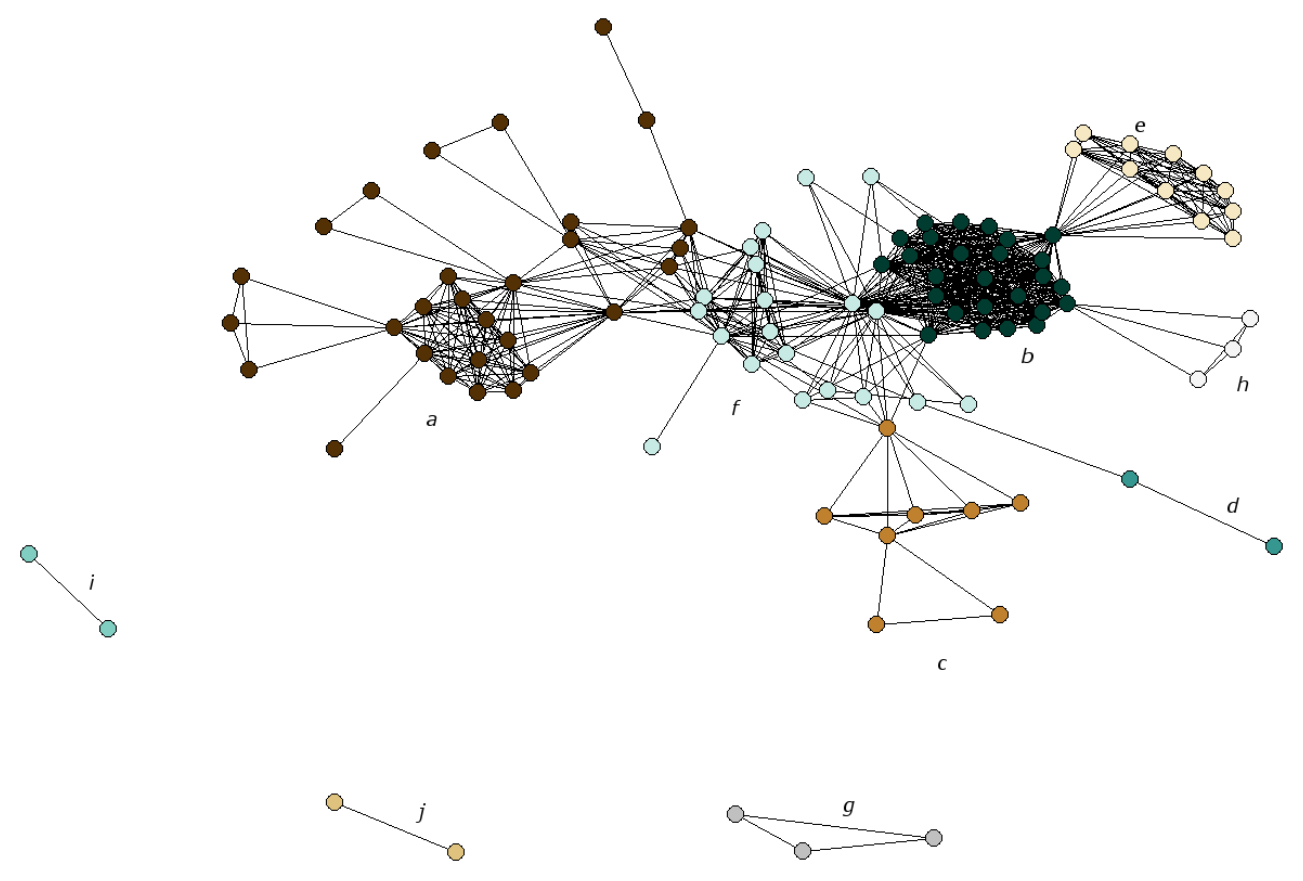

3c. 1990s

N of nodes: 106

Sum of ties: 2412 

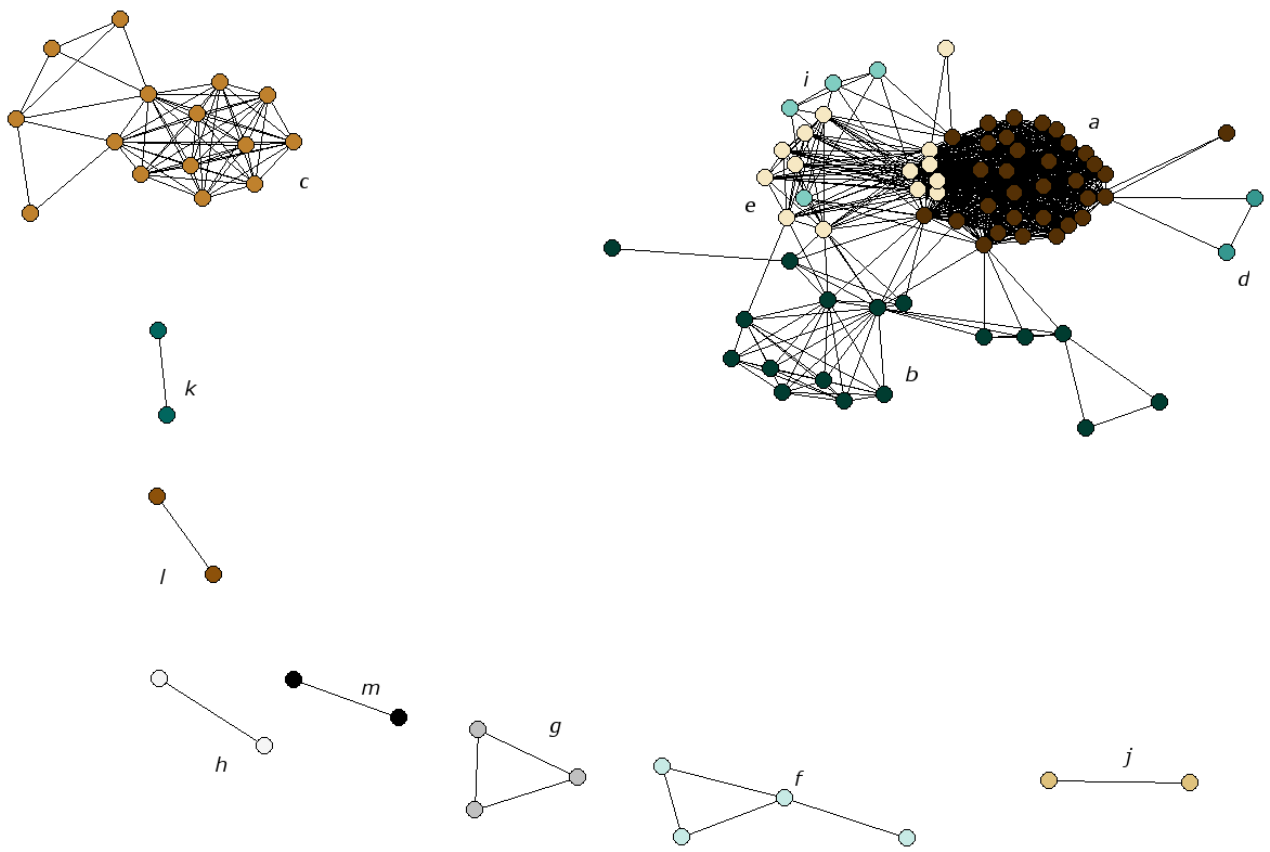

3d. 2000s

$\mathrm{N}$ of nodes: 101

Sum of ties: 1904 
TABLE 1. Frequency of Study of Comparative Cases by Revolutionary Attributes, 19702009

\begin{tabular}{|c|c|c|c|c|c|}
\hline Attribute & $\begin{array}{l}1970- \\
2009\end{array}$ & 1970s & $1980 \mathrm{~s}$ & $1990 \mathrm{~s}$ & $2000 \mathrm{~s}$ \\
\hline \multicolumn{6}{|l|}{ Era: } \\
\hline Before 1500 & 3 & 0 & 1 & 1 & 1 \\
\hline $1500-1775$ & 24 & 2 & 6 & 12 & 4 \\
\hline 1776-1913 & 123 & 33 & 16 & 47 & 27 \\
\hline 1914-1945 & 68 & 20 & 12 & 18 & 18 \\
\hline 1946-1988 & 367 & 45 & 78 & 163 & 81 \\
\hline 1989 on & 54 & - & - & 13 & 41 \\
\hline \multicolumn{6}{|l|}{ Region: } \\
\hline W. Europe/Anglo N. America & 91 & 20 & 16 & 29 & 26 \\
\hline E. Europe/former USSR & 103 & 10 & 13 & 27 & 53 \\
\hline Latin America/Caribbean & 243 & 22 & 48 & 129 & 44 \\
\hline Middle East/N. Africa & 65 & 12 & 10 & 28 & 15 \\
\hline Sub-Saharan Africa & 46 & 13 & 8 & 11 & 14 \\
\hline Asia & 89 & 23 & 18 & 28 & 20 \\
\hline Global/Multi-region & 2 & 0 & 0 & 2 & \\
\hline \multicolumn{6}{|l|}{ Primary mode of contention: } \\
\hline Insurgency, terrorism, civil war & 334 & 58 & 74 & 138 & 64 \\
\hline Mass uprising, social movement & 177 & 23 & 26 & 63 & 65 \\
\hline From above, coup, repression & 40 & 11 & 3 & 17 & 9 \\
\hline Interstate war, cross-border & 5 & 1 & 2 & 0 & 2 \\
\hline Other, complex & 30 & 4 & 2 & 11 & 13 \\
\hline Negative case & 53 & 3 & 6 & 25 & 19 \\
\hline \multicolumn{6}{|l|}{ Contenders' primary ideological basis: } \\
\hline Leftist, Marxist, anarchist & 257 & 34 & 55 & 119 & 49 \\
\hline Democratic, republican, inclusive & 140 & 18 & 13 & 45 & 64 \\
\hline National-separatist, anti-colonial & 83 & 28 & 18 & 21 & 16 \\
\hline Religious & 38 & 0 & 8 & 20 & 10 \\
\hline Reactionary, right-wing, statist & 22 & 8 & 3 & 6 & 5 \\
\hline Other, complex & 46 & 9 & 10 & 18 & 9 \\
\hline Negative case & 53 & 3 & 6 & 25 & 19 \\
\hline \multicolumn{6}{|l|}{ Outcome: } \\
\hline Social revolution & 256 & 42 & 52 & 109 & 53 \\
\hline Political revolution, regime change & 136 & 32 & 15 & 35 & 54 \\
\hline Ongoing contention, failure & 149 & 18 & 33 & 65 & 33 \\
\hline Other, complex & 45 & 5 & 7 & 20 & 13 \\
\hline Negative case & 53 & 3 & 6 & 25 & 19 \\
\hline
\end{tabular}


$\mathrm{N}$ of cases

$\mathrm{N}$ of unique cases

$\mathrm{N}$ of studies

Mean cases per study

\begin{tabular}{ccccc}
639 & 100 & 113 & 254 & 172 \\
203 & 51 & 59 & 107 & 101 \\
148 & 24 & 31 & 54 & 39 \\
4.3 & 4.1 & 3.7 & 4.7 & 4.4 \\
& & & & \\
\hline
\end{tabular}


TABLE 2. Cases of Revolution Studied Comparatively Ten or More Times, 1970-2009

\begin{tabular}{lcc}
\hline Event & $\begin{array}{c}\text { N of } \\
\text { Times } \\
\text { Studied }\end{array}$ & $\begin{array}{c}\text { Normalized } \\
\text { Degree Centrality }\end{array}$ \\
\hline Nicaragua, 1979 & 39 & \\
Cuba, 1959 & 31 & 4.93 \\
Russia, 1917 & 30 & 2.35 \\
France, 1789 & 24 & 2.17 \\
Iran, 1979 & 23 & 2.40 \\
El Salvador, 1980 & 22 & 3.59 \\
China, 1927 & 18 & 2.65 \\
Vietnam, 1946 & 17 & 2.57 \\
Mexico, 1910 & 14 & 2.52 \\
Guatemala, 1960 & 12 & 3.19 \\
Bolivia, 1952 & 11 & 1.83 \\
England, 1642 & 10 & 1.36 \\
Mean all cases & & .64 \\
\end{tabular}


TABLE 3. Cluster Size, Density, E-I Score, and Exemplars from Louvain Community Detection Algorithm, 1970-2009

\begin{tabular}{|c|c|c|c|c|c|}
\hline Cluster & Nodes & $\begin{array}{c}\text { Ties } \\
\text { within } \\
\text { Group } \\
\end{array}$ & $\begin{array}{c}\text { Density } \\
\text { within } \\
\text { Group }\end{array}$ & $\begin{array}{c}\text { E-I } \\
\text { Index }\end{array}$ & Exemplars \\
\hline$a$ & 53 & 1234 & .448 & -.514 & Vietnam, Iranian Islamic Revolution \\
\hline$b$ & 50 & 622 & .254 & -.591 & $\begin{array}{l}\text { Russian Revolution, French } \\
\text { Revolution }\end{array}$ \\
\hline$c$ & 34 & 1844 & 1.643 & -.473 & $\begin{array}{l}\text { Cuban Revolution, Nicaraguan } \\
\text { Revolution }\end{array}$ \\
\hline$d$ & 20 & 112 & .295 & -.189 & $\begin{array}{l}\text { Malay Emergency, Mau Mau } \\
\text { Rebellion }\end{array}$ \\
\hline$e$ & 15 & 148 & .705 & -1.000 & Orange Revolution, Rose Revolution \\
\hline$f^{a}$ & 10 & 90 & 1.000 & -.250 & $\begin{array}{l}\text { Brazilian Revolution of } 1930 \text {, } \\
\text { Albanian }\end{array}$ \\
\hline$g$ & 9 & 44 & .611 & -.700 & $\begin{array}{l}\text { Solidarity, Hungarian Uprising of } \\
1956\end{array}$ \\
\hline$h^{\mathrm{b}}$ & 3 & 6 & 1.000 & -1.000 & $\begin{array}{l}\text { Arab Nationalism, Marxism-Leninist } \\
\text { Wave }\end{array}$ \\
\hline$i \mathrm{~b}$ & 3 & 6 & 1.000 & -1.000 & $\begin{array}{l}\text { War of Spanish Succession, } \\
\text { Camisard } \\
\text { Revolt }\end{array}$ \\
\hline$j^{\mathrm{b}}$ & 2 & 2 & 1.000 & -1.000 & Estonia 1989, Latvia 1989 \\
\hline$k \mathrm{~b}$ & 2 & 2 & 1.000 & -1.000 & Irish Nationalists, Narodnya Volna \\
\hline$l^{\mathrm{b}}$ & 2 & 2 & 1.000 & -1.000 & $\begin{array}{l}\text { Rwandan Genocide, Sri Lankan Civil } \\
\text { War }\end{array}$ \\
\hline Network & 203 & 3512 & .129 & -.508 & \\
\hline
\end{tabular}

Note:

a) From primarily one study

b) From only one study (isolated subgraph) 
TABLE 4. Ten Most Frequent Comparisons of Revolutions, 1970-2009

\begin{tabular}{llc}
\hline Case 1 & Case 2 & $\begin{array}{c}\text { N of } \\
\text { Comparisons }\end{array}$ \\
\hline Nicaragua, 1979 & Cuba, 1959 & 20 \\
Russia, 1917 & France, 1789 & 18 \\
Nicaragua, 1979 & El Salvador, 1980 & 17 \\
Nicaragua, 1979 & Iran, 1979 & 13 \\
El Salvador, 1980 & Guatemala, 1960 & 11 \\
Russia, 1917 & China, 1927 & 11 \\
Nicaragua, 1979 & Guatemala, 1960 & 10 \\
Cuba, 1959 & Vietnam, 1946 & 9 \\
France, 1789 & England, 1642 & 9 \\
Cuba, 1959 & Bolivia, 1952 & 9 \\
& & \\
N dyads & & 1756 \\
Mean tie strength & & 1.50 \\
\hline
\end{tabular}


TABLE 5. QAP Pearson Correlation of Revolutionary Cases with Same Attributes and Observed Dyads, 5000 Permutations

\begin{tabular}{|c|c|c|}
\hline Attribute & Whole Network & $2+$ Study Network \\
\hline Era of onset & -.023 & $.289 * * *$ \\
\hline Region of occurrence & .004 & $.414^{* * *}$ \\
\hline Mode of contention & -.004 & $.132^{* * *}$ \\
\hline Ideological basis & .006 & $.151^{* * *}$ \\
\hline Outcome & .005 & $.116^{* * *}$ \\
\hline
\end{tabular}


TABLE 6. Five Most Frequently Studied Cases of Revolution by Decade

\begin{tabular}{|c|c|c|c|c|c|c|c|}
\hline \multicolumn{2}{|l|}{ 1970s } & \multicolumn{2}{|c|}{$1980 \mathrm{~s}$} & \multicolumn{2}{|c|}{$1990 \mathrm{~s}$} & \multicolumn{2}{|c|}{$2000 \mathrm{~s}$} \\
\hline Event & $\mathbf{N}$ & Event & $\mathbf{N}$ & Event & $\mathbf{N}$ & Event & $\mathbf{N}$ \\
\hline Russia, 1917 & 8 & Nicaragua, 1979 & 11 & Nicaragua, 1979 & 21 & Nicaragua, 1979 & 7 \\
\hline China, 1911 & 6 & Cuba, 1959 & 8 & Iran, 1979 & 13 & Russia, 1917 & 6 \\
\hline Cuba, 1959 & 6 & El Salvador, 1980 & 6 & Cuba, 1959 & 12 & Ukraine, 2004 & 6 \\
\hline Japan, 1867 & 5 & France, 1789 & 5 & El Salvador, 1980 & 11 & Cuba, 1959 & 5 \\
\hline \multirow[t]{4}{*}{ Vietnam, 1946} & 5 & Iran, 1979 & 5 & France, 1789 & 11 & El Salvador, 1980 & 5 \\
\hline & & Russia, 1917 & 5 & Russia, 1917 & 11 & Georgia, 2003 & 5 \\
\hline & & Vietnam, 1946 & 5 & & & Iran, 1979 & 5 \\
\hline & & & & & & Serbia, 1999 & 5 \\
\hline Mean case popularity & 2.0 & & 1.9 & & 2.4 & & 1.7 \\
\hline
\end{tabular}


TABLE 7. Five Most Frequent Comparisons of Revolutions by Decade

\begin{tabular}{|c|c|c|c|c|c|}
\hline \multicolumn{3}{|c|}{$1970 \mathrm{~s}$} & \multicolumn{3}{|c|}{$1980 \mathrm{~s}$} \\
\hline Case 1 & Case 2 & $\mathbf{N}$ & Case 1 & Case 2 & $\mathbf{N}$ \\
\hline Russia, 1917 & China, 1911 & 5 & Nicaragua, 1979 & Cuba, 1959 & 5 \\
\hline Russia 1917 & France, 1789 & 4 & Nicaragua, 1979 & $\begin{array}{l}\text { El Salvador, } \\
1980\end{array}$ & 5 \\
\hline France 1789 & China, 1911 & 3 & Cuba, 1959 & Bolivia, 1952 & 3 \\
\hline Japan, 1867 & China, 1911 & 3 & France, 1789 & England, 1642 & 3 \\
\hline France, 1789 & Prussia, 1806 & 3 & Nicaragua 1979 & Iran 1979 & 3 \\
\hline Russia 1917 & Prussia, 1806 & 3 & Russia, 1917 & France, 1789 & 3 \\
\hline \multirow{2}{*}{\multicolumn{2}{|c|}{$\begin{array}{l}\mathrm{N} \text { dyads } \\
\text { Mean tie strength }\end{array}$}} & 232 & \multirow{2}{*}{\multicolumn{2}{|c|}{$\begin{array}{l}\mathrm{N} \text { dyads } \\
\text { Mean tie strength }\end{array}$}} & 189 \\
\hline & & 1.14 & & & 1.15 \\
\hline \multicolumn{3}{|c|}{$\underline{1990 s}$} & \multicolumn{3}{|c|}{$\underline{2000 \mathrm{~s}}$} \\
\hline Case 1 & Case 2 & $\mathbf{N}$ & Case 1 & Case 2 & $\mathbf{N}$ \\
\hline Nicaragua, 1979 & Cuba, 1950 & 11 & Nicaragua, 1979 & Cuba, 1959 & 4 \\
\hline Nicaragua. 1979 & $\begin{array}{l}\text { El Salvador, } \\
1980\end{array}$ & 9 & Nicaragua, 1979 & Iran, 1979 & 4 \\
\hline Russia, 1917 & France, 1789 & 8 & Ukraine, 2004 & Serbia, 2000 & 4 \\
\hline El Salvador, 1980 & Guatemala, 1960 & 7 & Ukraine, 2004 & Georgia, 2003 & 4 \\
\hline Nicaragua, 1979 & Guatemala, 1960 & 6 & Russia, 1917 & China, 1946 & 3 \\
\hline \multirow[t]{2}{*}{ Nicaragua, 1979} & Iran & 6 & Russia, 1917 & France, 1789 & 3 \\
\hline & & & Cuba, 1959 & $\begin{array}{l}\text { El Salvador, } \\
1980\end{array}$ & 3 \\
\hline $\mathrm{N}$ dyads & & 720 & Nicaragua, 1979 & $\begin{array}{l}\text { El Salvador, } \\
1980\end{array}$ & 3 \\
\hline \multirow[t]{5}{*}{ Mean tie strength } & & 1.68 & $\begin{array}{l}\text { El Salvador, } \\
1980\end{array}$ & Peru, 1980 & 3 \\
\hline & & & Cuba, 1959 & Vietnam, 1946 & 3 \\
\hline & & & Nicaragua, 1979 & Vietnam, 1946 & 3 \\
\hline & & & $\mathrm{N}$ dyads & & 895 \\
\hline & & & Mean tie strength & & 1.06 \\
\hline
\end{tabular}


TABLE 8. QAP Pearson Correlation of Revolutionary Cases with Same Attributes and Observed Dyads by Decade, 5000 Permutations

\begin{tabular}{|c|c|c|c|c|}
\hline Attribute & 1970 s & $1980 \mathrm{~s}$ & $1990 \mathrm{~s}$ & $2000 \mathrm{~s}$ \\
\hline Era of onset & $.117^{* *}$ & $.204 * * *$ & $.282^{* * *}$ & $.319^{* * *}$ \\
\hline Region of occurrence & $.131 * * *$ & $.372^{* * *}$ & $.448^{* * *}$ & $.204 * * *$ \\
\hline Mode of contention & $.082 *$ & $.117 * * *$ & $.168^{* * *}$ & $.107 * * *$ \\
\hline Ideological basis & $.160^{* * *}$ & $.201 * * *$ & $.209 * * *$ & .030 \\
\hline Outcome & .045 & $.086 * * *$ & $.207 * * *$ & $.055^{* * *}$ \\
\hline
\end{tabular}


TABLE 9. Distribution of Attributes of Unique Cases in Comparative Case Studies and Tilly's European Revolutions (1993)

\begin{tabular}{|c|c|c|}
\hline Attribute & $\begin{array}{c}\% \text { of } \\
\text { Unique Cases in } \\
\text { Comparative Studies }^{\mathrm{a}}\end{array}$ & $\begin{array}{c}\% \text { of } \\
\text { Tilly's Revolutionary } \\
\text { Situations } \\
\end{array}$ \\
\hline Mean year of onset (S.D.) & $1925(58)$ & $1877(53)$ \\
\hline \multicolumn{3}{|l|}{ Region: } \\
\hline Low Countries & 0 & 2.7 \\
\hline Iberia & 10.3 & 39.8 \\
\hline Balkans \& Hungary & 33.3 & 39.8 \\
\hline British Isles & 7.7 & 3.5 \\
\hline French states & 15.4 & 7.1 \\
\hline Russian states & 25.6 & 7.1 \\
\hline European wide & 7.7 & 0 \\
\hline \multicolumn{3}{|l|}{ Primary mode of contention: } \\
\hline Insurgency, etc. & 23.1 & 40.7 \\
\hline Mass uprising, etc. & 59.0 & 26.6 \\
\hline Rev from above, etc. & 7.7 & 22.1 \\
\hline Interstate war, crossborder & 5.3 & 3.5 \\
\hline Other, complex & 5.3 & 7.1 \\
\hline \multicolumn{3}{|c|}{ Contenders' primary ideological basis: } \\
\hline Leftist, etc. & 25.6 & 8.9 \\
\hline Democratic, etc. & 51.3 & 27.4 \\
\hline Nationalist-separatist, etc. & 12.8 & 35.4 \\
\hline Religious, etc. & 0 & 0 \\
\hline Reactionary, etc. & 2.6 & 17.7 \\
\hline Other, unclear, complex & 7.7 & 10.6 \\
\hline \multicolumn{3}{|l|}{ Outcome: } \\
\hline Social revolution & 25.6 & 6.2 \\
\hline Political revolution & 28.2 & 33.6 \\
\hline Contention, failure & 33.3 & 54.0 \\
\hline Other, complex, unclear & 12.8 & 6.2 \\
\hline $\mathrm{N}$ of unique cases & 39 & 113 \\
\hline
\end{tabular}

Note: a) The data for comparison include only events from 1789-1992 that occurred in Tilly's six regions of Europe, not including negative and counterfactual cases. 